\title{
POXVIRUS TROPISM
}

Grant McFadden

Abstract | Despite the success of the WHO-led smallpox eradication programme a quarter of a century ago, there remains considerable fear that variola virus, or other related pathogenic poxviruses such as monkeypox, could re-emerge and spread disease in the human population. Even today, we are still mostly ignorant about why most poxvirus infections of vertebrate hosts show strict species specificity, or how zoonotic poxvirus infections occur when poxviruses occasionally leap into novel host species. Poxvirus tropism at the cellular level seems to be regulated by intracellular events downstream of virus binding and entry, rather than at the level of specific host receptors as is the case for many other viruses. This review summarizes our current understanding of poxvirus tropism and host range, and discusses the prospects of exploiting host-restricted poxvirus vectors for vaccines, gene therapy or tissue-targeted oncolytic viral therapies for the treatment of human cancers.

\section{ZOONOSIS}

The infection of a novel host species, usually humans, by an animal virus that normally does not use man as a reservoir host.
Department of Microbiology and Immunology, University of Western Ontario, and Robarts Research Institute, Siebens-Drake Building, Room 133, 1400 Western Road, London, Ontario N6G 2V4, Canada. e-mail: mcfadden@robarts.ca doi:10.1038/nrmicro1099
Despite remarkable advances in the control and treatment of infectious diseases, the problem of emerging and re-emerging pathogens is likely to be one of the main issues of medical and public health in the twenty-first century ${ }^{1}$. Viral diseases are of particular concern because advances in the field of antiviral drugs have lagged behind those of bacteriocidal drugs and antibiotics. Instead, the use of vaccines and good medical practices remain the traditional strategies to control viral infections. Also, particularly in the case of emerging viral pathogens, the development of antiviral therapies and vaccines can lag behind the time of viral emergence by years, or even decades. As the experience with severe acute respiratory syndrome (SARS) taught us, new members from neglected virus families can cross into humans from unsuspected reservoirs, necessitating rapid advances in our understanding of novel virus-host dynamics before the development of effective vaccines and drugs can even be contemplated $^{2}$. Indeed, if there is one certainty in this new century, it is that viral pathogens will continue to emerge in the human population. It is therefore worthwhile to consider lessons that have been learned from the one viral pathogen — variola virus — that has killed more members of the human population over the span of recorded history than all other infectious diseases combined.
When, in 1980, the World Health Organization (WHO) certified that the world was finally free of smallpox as an extant human disease, all known stocks of variola virus were rounded up and ceremoniously relegated to 'death row's. The two remaining WHOapproved variola virus stocks were stored in 'frozen limbo'; however, fears have increased that these official stocks are not the only ones remaining ${ }^{4,5}$. The terrorist attacks in the United States on 11 September 2001, which were closely followed by anthrax release, only increased fears that variola virus stocks could be acquired and used as deliberate agents of mass mortality. Needless to say, the subsequent increase in funding to research programmes that aim to counter this threat has resulted in the resurgence of research into select pathogens that exhibit human tropism.

Today, the focus of research on variola virus is directed towards the development of novel antiviral drugs and safer vaccines ${ }^{6,7}$, but it is also an appropriate juncture to ask a more fundamental question: why is variola virus a human-specific pathogen? One of the reasons that determined the success of the WHO smallpox eradication programme was the fact that no animal reservoirs of variola virus have ever been found. Many poxviruses are capable of zoonotically infecting man $^{8-10}$, and it is likely that variola virus is derived from an ancient zoonosis that originated from an animal host species that 


\begin{tabular}{|c|c|c|c|c|}
\hline Poxvirus & Genus & Reservoir host & Zoonotic host & Replication range in cultured cells \\
\hline Variola & Orthopoxvirus & Human & None & Most mammalian cells \\
\hline Monkeypox & Orthopoxvirus & Rodents, squirrels & Monkeys, humans & Most mammalian cells, not PEK cells \\
\hline Cowpox & Orthopoxvirus & Rodents & $\begin{array}{l}\text { Humans, cows, cats, } \\
\text { foxes, zoo animals }\end{array}$ & Most mammalian cells, including $\mathrm{CHO}$ cells \\
\hline Ectromelia & Orthopoxvirus & Rodents & Laboratory mice & Most mammalian cells, not $\mathrm{CHO}$ cells \\
\hline Orf ${ }^{\ddagger}$ & Parapoxvirus & Ungulates & Humans, cats & Primary ovine and bovine fibroblasts \\
\hline Tanapox & Yatapoxvirus & Rodents? Insects? & Humans, monkeys & Selected primate cells \\
\hline Myxoma & Leporipoxvirus & Rabbit (brush) & Rabbit (European) & $\begin{array}{l}\text { Rabbit, selected primate and human tumour } \\
\text { cells }\end{array}$ \\
\hline
\end{tabular}

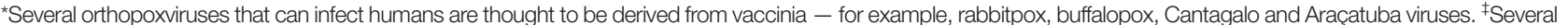
parapoxviruses can infect man - for example, paravaccinia, bovine papular stomatitis, deerpox and sealpox viruses. CHO; Chinese hamster ovary; PEK, pig embryo kidney.

is now extinct ${ }^{4}$. In general, poxviruses show species specificities that range from narrow to broad, but we still know little about the fundamental mechanisms that mediate the host tropism of individual poxviruses. Even if variola virus never again infects humans, there are other poxviruses that can cause serious human disease. In 2003, an outbreak of human monkeypox occurred in the mid-western United States due to the inadvertent importation of monkeypox virus in a shipment of rodents from west Africa ${ }^{11,12}$. Fortunately, the strain that caused this outbreak was more benign in humans than the more pathogenic variant that is found in central Africa, which results in mortality rates of $10-15 \%$ (REFS 13,14). The animal reservoir for monkeypox in Africa remains unknown, although several indigenous members of the squirrel species are likely candidates, but the features that predispose this virus to zoonotically infect man and other primates are unknown ${ }^{15}$. If monkeypox were to establish a reservoir status in a susceptible north American rodent species, such as prairie $\operatorname{dog} \mathrm{s}^{16}$, the public health consequences would be considerable.

This review considers what is currently known about the fundamental mechanisms that mediate the species specificities and host tropisms of poxviruses, and discusses the prospects for exploiting hostrestricted poxvirus vectors for vaccines, gene therapy and tissue-targeted oncolytic viral therapies.

\section{Three levels of viral tropism}

Part of the challenge in identifying specific poxvirus/ host tropism determinants is the fact that at least three levels of tropism can be defined, each of which involves different aspects of virus-host interactions. The first level of tropism - cellular tropism - refers to the observation that virus replication can be permissive, semi-permissive or abortive in cultured cells of different lineages or species. The second level refers to the frequently observed increased levels of virus replication in specific host organs or tissues, which can be influenced by factors that mediate cellular tropism as well as by tissue-specific antiviral responses. The third level, which manifests with overt pathogenesis and symptoms of disease in the infected organism, is influenced by the first two levels of tropism as well as by the overall host immune and inflammatory responses. Each of the three tropism levels have important roles in determining whether a virus will exhibit tropism for a given host species. In general, in a reservoir host, the virus causes relatively low pathogenicity and is harboured and transmitted while resulting only in subclinical infection. Zoonotic infections, however, are generally discovered only after species transfers that lead to increased virus pathogenicity or novel disease.

Although many poxviruses show strict species specificities in terms of their reservoir or zoonotic hosts, in tissue-culture cells, these specificities can vary markedly such that cells derived from vertebrate species that are not considered PERMISSIVE HOSTS can sometimes be productively infected in vitro. For example, myxoma virus is a rabbit-specific poxvirus that has been used to eradicate feral rabbits in Australia ${ }^{17}$ but, in vitro, myxoma virus replicates robustly in selected transformed cells that are derived from humans and other primates ${ }^{18}$. In fact, in vitro, individual poxviruses exhibit a unique host-cell specificity that can be distinct from its in vivo host range (TABLE 1).

For many other viruses, tropism specificity in cultured cells is mainly determined by specific receptors that need to be engaged for virus binding and entry ${ }^{19,20}$ but, for poxviruses, no specific host-cell receptors have been identified. Although there are correlations between the expression levels of cell surface receptors and permissiveness to certain poxviruses ${ }^{21,22}$, subsequent work has shown that poxviruses bind and enter both permissive and RESTRICTIVE CELLS, but downstream intracellular events are aborted specifically in restrictive cell ${ }^{23}$. Therefore, poxviruses can probably bind to and enter a wide range of mammalian cells, but the ability of a given poxvirus to fully complete the replication cycle varies markedly between cells of different lineages or species origins.

The second and third levels of poxvirus tropism - tissue and organism tropisms - determine the distribution and dissemination of the virus in an infected host, and both tropisms affect the ability of the virus to spread between hosts. Therefore, virus spread and pathogenesis are intimately influenced by the innate 

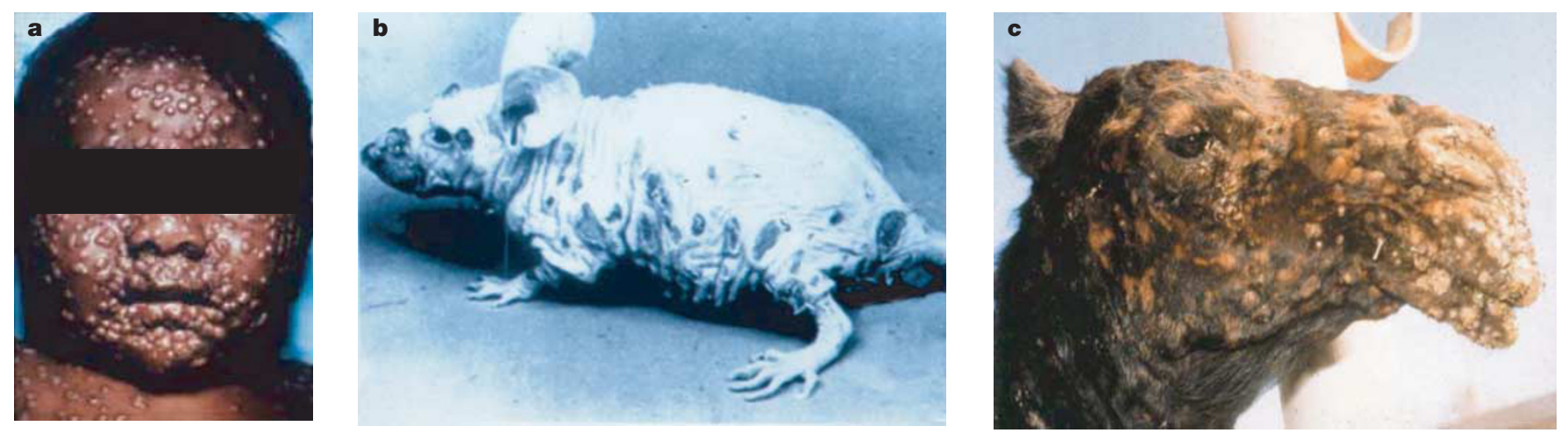

Figure 1 | Examples of host-restricted poxviruses. Some poxviruses, like variola major (smallpox) of humans (a), ectromelia virus (mousepox) of mice (b) or camelpox virus of camels (c) remain largely restricted to one host species and rarely, if ever, cause zoonotic infections outside of that species. Other poxviruses (TABLE 1) can infect multiple zoonotic host species. Part $\mathbf{a}$ is reproduced with permission from the WHO web site (see the Online links box); part $\mathbf{b}$ is reproduced with permission from REF. 199 ( ) (1982) Academic Press; part c was kindly provided by U. Wernery (United Arab Emirates) and H. Meyer (Germany).

and acquired immune responses of the infected host, which are themselves manipulated by the numerous immunomodulatory proteins that are elaborated by poxviruses ${ }^{24}$. Although the three levels of tropism are highly interdependent, each has unique features that interact to regulate the specificity of poxvirus-host interactions. Ultimately, it is the summation of these interactions that determines which infections will be permissive in a specific host species, and which of these will manifest as overt disease.

\section{Cellular tropism: poxvirus replication}

Poxviruses that infect vertebrates are of the subfamily Chordopoxvirinae and share several biological features. All are large, brick-shaped DNA viruses, with genomes that range from 130-300 kb, and all replicate exclusively in the cytoplasm of infected cells ${ }^{25}$. The Chordopoxvirinae are subdivided into eight genera, and members of at least half of these (the orthopoxviruses, parapoxviruses, molluscipoxvirus and yatapoxviruses) can infect man, either exclusively — for example, variola virus and molluscum contagiosum virus - or zoonotically ${ }^{8,9}$. The consequences of these infections range from severe disease associated with high mortality (FIG. 1) to benign infections that resolve over time ${ }^{10}$. Poxvirus particles from members of the various genera are morphologically similar (FIG. 2) and the main viral proteins that comprise poxvirus virions are thought to be largely conserved in terms of both structure and function.

So far, several dozen poxviruses have been sequenced and an NIH-sponsored web site (see the Poxvirus Bioinformatics Resource Center in the Online links box) is dedicated to maintaining an up-to-date repository of all the publicly available poxvirus genome sequences. These poxvirus genomes share several common features that collectively denote membership of the poxvirus family. All have linear double-stranded DNA genomes that include terminal inverted repeat sequences and hairpin termini and which comprise several hundred closely spaced open reading frames ${ }^{25}$. Of these open reading frames, at least 90 are specifically conserved among the various poxviruses and are required for poxvirus replication and morphogenesis, whereas the remainder are more divergent, owing to differences in adaptive evolution between the various poxvirus members ${ }^{26-28}$. It is the specific repertoire of these so-called non-conserved genes that gives each poxvirus its unique characteristics of host range, immunomodulation and pathogenesis ${ }^{24}$. Generally, poxvirus genes that are non-essential for replication in tissue-culture cells, but that influence the pathological profile of the virus in an infected host, are referred to as virulence genes, and targeted gene-knockout analysis has been used to identify the roles of many such poxvirus genes, particularly in vaccinia and myxoma viruses $^{29-31}$. The deletion of some of these virulence genes can result in the inability of the virus to replicate in a subset of cultured cells that are normally permissive for the wild-type virus ${ }^{29}$. These so-called hostrange genes have generated some insights into the nature of poxvirus tropism at the level of the infected cell and will be discussed separately below.

As illustrated in FIG. 3, the poxvirus replication cycle is a complex sequence of cytoplasmic events that begins with binding to the cell surface and subsequent fusion of virus and mammalian cell membranes. The intracellular replication cycle has been most well studied for vaccinia virus, which is the vaccine strain that was used to eradicate smallpox, but the essential features are highly conserved amongst other poxviruses ${ }^{25}$. Two distinct infectious virus particle types - the intracellular mature virus (IMV) and the extracellular enveloped virus (EEV) - can initiate the infectious cycle $^{32}$. The IMV and EEV virions differ in their surface glycoproteins and in the number of wrapping membranes, and they are thought to enter cells by different mechanisms $s^{33-35}$. So far, several virion proteins have been shown to be crucial for binding of the virion to the cell surface, but the cell determinants of binding are thought to be ubiquitously expressed GLYCOSAMINOGLYCANS or components of the extracellular matrix ${ }^{36-40}$. After binding, the fusion event between the virion and the host cell membranes is still poorly understood, but at 
a

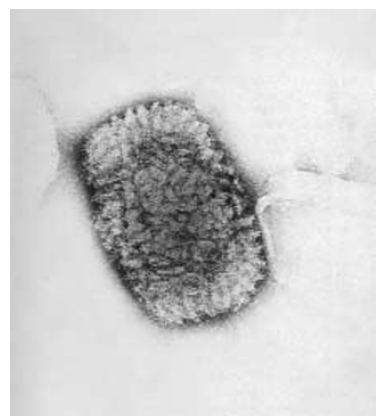

b

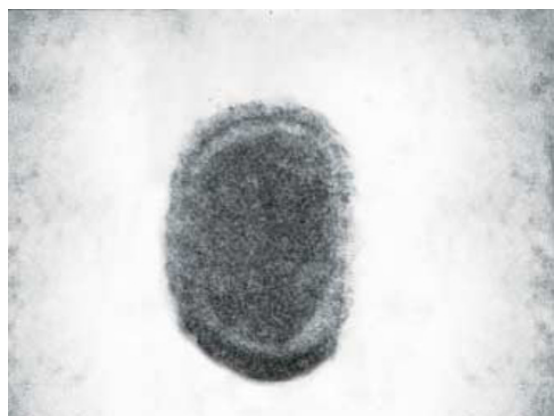

Figure 2 | All poxviruses are morphologically similar. Electron microscopic images reveal that poxviruses share common features of size and shape. For example, vaccinia virus (a; image courtesy of $\mathrm{CDC}$ ) can infect a broad range of hosts but is very similar in size, shape and morphology to poxviruses (intracellular mature virus (IMV) forms) that are highly host restricted, such as molluscum contagiosum virus (b; image courtesy of CDC/Fred Murphy/Sylvia Whitfield), which has only been shown to infect man and replicates exclusively in human basal keratinocytes.

least one conserved virion protein (VV-A28) has been linked to this fusion/entry event that ultimately releases the virion core structure into the cytoplasm ${ }^{41}$. Although no specific cell receptors are known to be required for virion fusion and entry, there is evidence that virion binding and/or entry is associated with rapid signalling events in several host protein-kinase cascades, and it is likely that these signalling events can influence subsequent replication stages ${ }^{35,42-44}$. The study of signalling that is initiated by virus entry in mammalian cells is a growing field ${ }^{45}$, particularly owing to increasing evidence of the crucial role of cell receptors, such as TOLLLIKE RECEPTORS (TLRs), that act as 'sentries' that activate antiviral pathways ${ }^{46}$. The precise roles of TLRs in the control of poxvirus infections remain to be elucidated, but there is evidence that at least some poxviruses can block TLR signalling ${ }^{47,48}$.

Once the virion and host membranes have fused and the virus core has been released into the cytoplasm, the endogenous RNA polymerase and encapsidated transcription factors that comprise the viral transcriptosome begin the first cascade of early viral gene expression, which synthesizes viral mRNA under the control of viral early promoters ${ }^{25,49}$. Then, by a poorly understood process known as core (or second stage) uncoating, as-yet-unidentified host and viral factors induce the dissolution of the core structure. This uncoating step releases the viral DNA into the cytoplasm, where it can function as a template for DNA replication and the subsequent waves of intermediate and late transcription. Unlike early transcription, which is believed to be exclusively under the control of viral transcriptosome factors that are encapsidated within the core, the subsequent intermediate and late transcription stages require cooperation with host-derived transcription factors that contribute to the efficiency of these latter two waves of viral gene expression ${ }^{50-56}$.

Concomitant with the accumulation of late viral gene products is the progressive morphogenesis and assembly of infectious virus particles, initially as IMV virions, which assemble and migrate via microtubulemediated trafficking and wrapping with Golgi-derived membranes to form intracellular enveloped virus (IEV).

The IEV form loses one of its outer membrane wrappings as it fuses with the cell membrane to form the cell-associated enveloped virus (CEV), which is either propelled towards neighouring cells by ACTIN-TAIL POLYMERIZATION under the virion, or is released directly as free EEV particles. It is thought that the CEV and EEV forms are particularly important for rapid cell-cell spread in vivo, whereas the IMV form probably contributes to virus dissemination only after late stage cell death and membrane rupture ${ }^{57,58}$. The actin-based extrusion of IEV and CEV is under the control of several host proteins, including N-WASP (neuronal Wiskott-Aldrich syndrome protein), Nck (novel cytoplasmic kinase), WIP (WASP-interacting protein) and kinases of the Src/Abl families ${ }^{59-61}$.

In addition to the host trans-acting factors mentioned above, poxviruses express an array of modulatory proteins that modify both the intracellular and extracellular environments of the infected cell. These virus-encoded proteins collectively modulate a wide range of antiviral defence responses that are triggered by the virus infection and which include important host pathways such as apoptosis, interferon induction of the antiviral state, stress-induced signalling cascades, MHC-restricted antigen presentation and pro-inflammatory pathways ${ }^{24}$. The particular host-response factors that are encoded by individual poxviruses are responsible for the ability of each poxvirus to respond to the various antiviral mechanisms that are encountered in the infected host, as well as during the progressive migration of the virus through diverse cell types and tissues.

\section{Restriction events in poxvirus-infected cells}

Our knowledge of which regulatory factors control the main intracellular steps that determine whether a given poxvirus infection will be permissive or restrictive is still relatively limited, but a few general observations can be made (TABLE 2). At the level of virion binding and entry, all of the currently known cellular determinants that are required for a poxvirus virion to bind and initiate virus-host membrane fusion are ubiquitous surface elements, such as glycosaminoglycans, or extracellular matrix components ${ }^{37-41}$. It is now believed that the binding and entry of poxviruses into mammalian cells is an efficient process, and any restriction events that limit poxvirus replication specifically in non-permissive cells occur after the virus has entered the cell and initiated the replication cycle. Even highly restricted poxviruses such as molluscum contagiosum virus, which cannot be propagated in vitro in any known cell line and which replicates productively only in human basal keratinocytes, can bind and enter non-permissive mammalian cells in culture ${ }^{62}$. Similarly, chordopoxviruses such as vaccinia virus can bind, enter and initiate the viral replication cycle even in non-permissive insect cells ${ }^{63}$. However, once the virus core enters the cytoplasm and initiates the first steps of early gene expression, the 'tug of war' between the infecting virus and the target cell begins in earnest. At least four categories of intracellular events have been identified as potential restriction points 


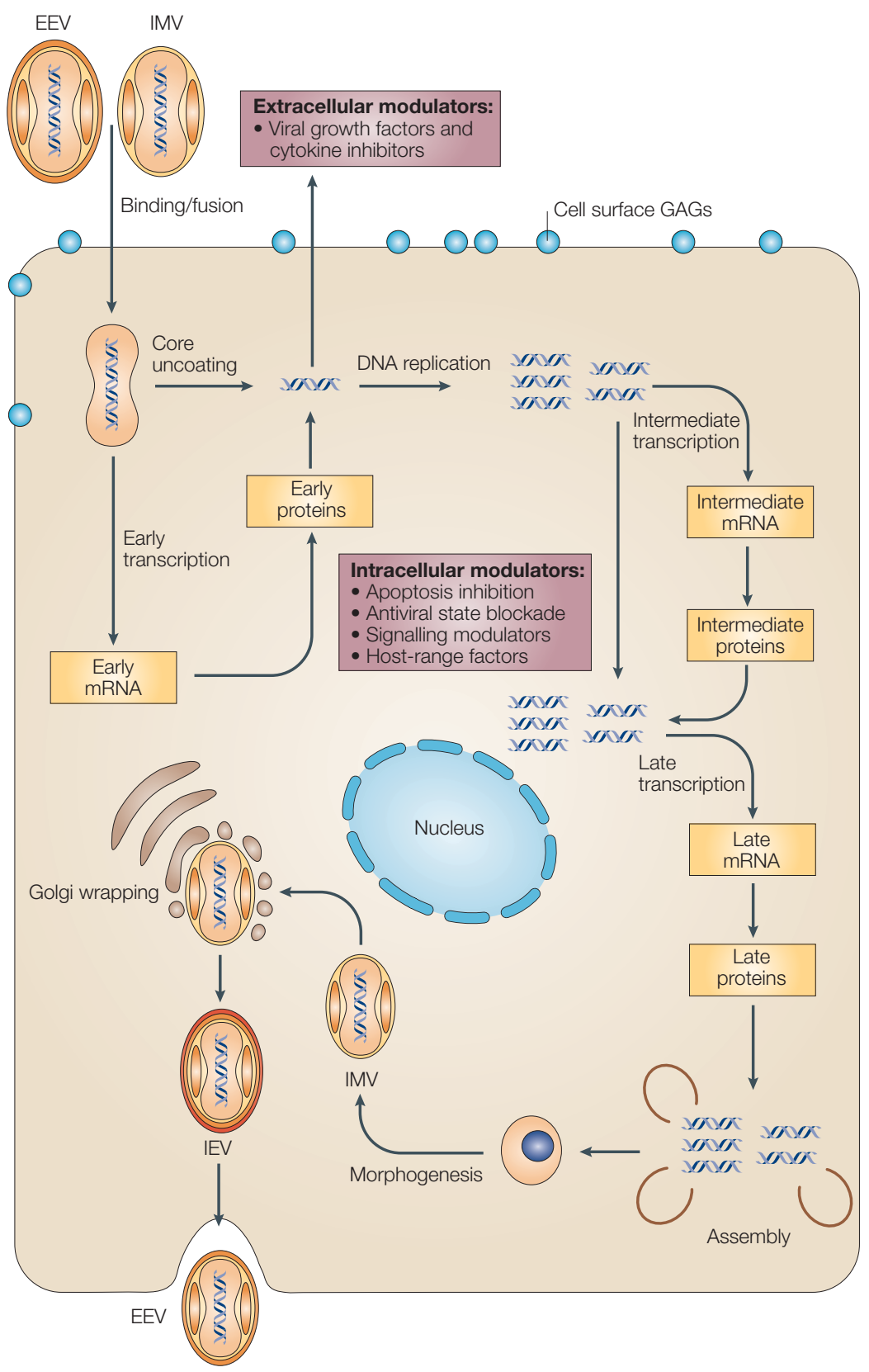

Figure 3 | Poxvirus replication cycle. All poxviruses replicate in the cytoplasm of infected cells by a complex, but largely conserved, morphogenic pathway. Two distinct infectious virus particles - the intracellular mature virus (IMV) and the extracellular enveloped virus $(E E V)-$ can initiate infection ${ }^{32}$. The IMV and EEV virions differ in their surface glycoproteins and in the number of wrapping membranes ${ }^{33-35}$. The binding of the virion is determined by several virion proteins and by glycosaminoglycans (GAGs) on the surface of the target cell or by components of the extracellular matrix. Fully permissive viral replication is characterized by three waves of viral mRNA and protein synthesis (known as early, intermediate and late), which are followed by morphogenesis of infectious particles. The initial intracellular mature virus (IMV) is transported via microtubules (not shown in the figure) and is wrapped with Golgi-derived membrane, after which it is referred to as an intracellular enveloped virus (IEV). The IEV fuses to the cell surface membrane to form cell-associated enveloped virus (CEV; not shown), which is either extruded away from the cell by actin-tail polymerization (not shown) or is released to form free EEV. EEV might also form by direct budding of IMV, therefore bypassing the IEV form. Poxviruses also express a range of extracellular and intracellular modulators, some of which are defined as host-range factors that are required to complete the viral replication cycle. Poxviruses can be markedly diverse in their portfolio of specific modulators and host-range factors, which determine tropism and host range. Non-permissive poxvirus infections generally abort at a point downstream of the binding/fusion step. for regulating whether a given poxvirus infection will proceed to completion, and it is likely that more such control checkpoints remain to be identified (TABLE 2).

Cell-cycle control. The first of these potentially regulatable events is the cell-cycle status of the infected cell. Poxviruses have been thought to be less S-phasedependent than many other viruses, but there is evidence that the ability of poxviruses to MITOGENICALLY STIMULATE quiescent cells markedly increases viral replication levels. Many poxviruses encode growth factors, as homologues of either epidermal growth factor (EGF) or vascular endothelial growth factor (VEGF), that act in a paracrine manner to stimulate the onset of mitosis in neighbouring cells, and targeted deletions of the growth factor genes of vaccinia and myxoma virus have been shown to result in severe attenuation in infected animals $^{24,29-31}$. There is also some evidence that poxviruses can directly perturb the activity of specific cell-cycle components in the infected cell, but whether there is a direct link with cell tropism is currently unknown ${ }^{64-66}$. Microarray data of HeLa cells that are infected with vaccinia virus strain WR indicate that, although the expression of most cellular genes is repressed, the expression of a small percentage $(\sim 3 \%)$ is robustly upregulated ${ }^{67}$. It would be of interest to compare and contrast these induced genes with the patterns of gene expression that are seen in comparable infections with host-restricted virus variants but, so far, the only available data is for the attenuated modified vaccinia virus Ankara (MVA), which induces the expression of many more cellular genes than the WR $\operatorname{strain}^{68}$.

Cell lineage and differentiation state. The second intracellular event that regulates the efficiency of poxvirus replication is the lineage and differentiation state of the infected cell. For example, some poxviruses are dependent on the precise differentiation state of the host cell, such as the restriction of productive replication of molluscum contagiosum virus to keratinocytes that arise from the basal epidermal layer of the skin, mentioned above. In this case, the cellular factors that are required for the virus to complete its replication cycle beyond the stage of early gene expression are unknown, but it is noteworthy that the molluscum contagiosum virus encodes fewer immunomodulatory proteins than any other poxvirus that can infect humans $s^{69,70}$. Another example of the dependence of poxvirus infection on the specific cell lineage is shown by studies using differentiated DENDRITIC CELLS. Owing to the importance of dendritic cells for the immunogenic responses to poxvirus-based vaccine vectors, many studies have been conducted to examine the ability of poxvirus-infected dendritic cells to present foreign antigens ${ }^{71-75}$. Interestingly, whereas vaccinia virus is permissive for most cell types, infection of either mature or immature dendritic cells results in abortive infection after early gene expression, indicating that these cells have some specific defect that renders them refractory to productive vaccinia virus infection ${ }^{76-80}$. Currently, the basis of the 


\begin{tabular}{|c|c|c|}
\hline Level of host-virus interactions & $\begin{array}{l}\text { Viral factors that require } \\
\text { host-cell components }\end{array}$ & $\begin{array}{l}\text { Interacting host-cell factors and } \\
\text { pathways }\end{array}$ \\
\hline \multicolumn{3}{|l|}{ Virus binding and entry } \\
\hline EEV binding & Unknown & Unknown \\
\hline IMV binding & W-A27, D8, H3 & Glycosaminoglycans, laminins \\
\hline Fusion/endocytosis & W-A28, others? & Host membranes, raft-dependent? \\
\hline \multicolumn{3}{|l|}{ Intracellular events } \\
\hline Cell-cycle control & Viral growth factors (VGF, vVEGF) & S-phase regulators, p53 \\
\hline Differentiation state & Unknown & Cell lineage factors \\
\hline $\begin{array}{l}\text { Complementing factors } \\
\text { Core uncoating } \\
\text { Transcription } \\
\text { Protein folding } \\
\text { Virion trafficking }\end{array}$ & $\begin{array}{l}\text { Core structural protein(s) (?) } \\
\text { Viral RNA polymerase complex } \\
\text { Core protein } 4 \text { a } \\
\text { VV-A36 of IEV }\end{array}$ & $\begin{array}{l}\text { Unknown } \\
\text { Intermediate/late transcription factors } \\
\text { Hsp90 } \\
\text { N-WASP, Nck, WIP, Src/Abl-kinases }\end{array}$ \\
\hline $\begin{array}{l}\text { Signal transduction } \\
\text { Antiviral state } \\
\text { Kinases } \\
\text { Signalling } \\
\text { Apoptosis }\end{array}$ & $\begin{array}{l}\text { VV-E3L/K3L, tyrosine phosphatase } \\
\text { Unknown targets } \\
\text { VV-KIL, N1L, A52R; MC159L; M150R } \\
\text { M-T5, M-T2, M-T4, M11L, W-F1L, } \\
\text { SPI-1, SPI-2, EV-p28 }\end{array}$ & $\begin{array}{l}\text { Interferon signalling, PKR, STAT } \\
\text { PAK1, ERK1/2 } \\
\text { NF-KB } \\
\text { Cell death machinery }\end{array}$ \\
\hline \multicolumn{3}{|c|}{$\begin{array}{l}\text { CEV, cell-associated enveloped virus; EEV: extracellular enveloped virus; ERK1/2, extracellular regulated kinases 1, 2; EV, ectromelia } \\
\text { virus; Hsp90, heat shock protein 90; IMV: intracellular mature virus; MC, molluscum contagiosum; M, myxoma; NF-kB, nuclear factor-kB; } \\
\text { Nck: Novel cytoplasmic kinase; N-WASP, neuronal Wiskott-Aldrich syndrome protein; PAK1, p21-activated kinase 1; PKR, protein } \\
\text { kinase R; SPI, serine proteinase inhibitor; STAT, signal transducer and activator of transcription; VGF, vaccinia growth factor; VVEGF, viral } \\
\text { vascular endothelial growth factor; VV, vaccinia virus; WIP, WASP-interacting protein. }\end{array}$} \\
\hline
\end{tabular}

deficiency of vaccinia replication in dendritic cells is unknown, but the identification of any complementing factor that is missing in dendritic cells, or a lineagespecific antiviral pathway, would be of considerable interest.

Complementing host factors. The third category of intracellular event that is required for poxvirus replication involves the many trans-acting factors that must be hijacked by the virus to complete its replication cycle. Some of these, such as the yet-to-be-identified hostcore-uncoating factor(s), are thought to exist because cell-to-cell differences are noted in the uncoating stage. Other essential host features that are required by poxviruses, such as the translational machinery in the cytoplasm, are ubiquitous in growing mammalian cells, and are not thought to directly influence tropism. However, the availability of trans-acting transcription factors from the host cell that are required as components for intermediate and late viral transcription, such as VITF-2, might be rate-limiting in certain cells ${ }^{50-52,56}$. Similarly, any deficits in important cell regulatory elements of the microtubule-based or actin-based motility machinery would be expected to compromise the morphogenesis or egress of infectious virus. One example of a trans-acting factor that has been shown to directly modulate poxvirus propagation is Hsp90 - a MOLECULAR CHAPERONE that associates with the viral factories and regulates the efficiency of vaccinia virus replication by interacting with the viral core protein $4 \mathrm{a}$, which is crucial for virion assembly ${ }^{81}$.

Signal transduction. The fourth category of intracellular events that regulate poxvirus replication is the diverse signal-transduction pathways that coordinate the intrinsic cell responses to the virus infection. Perhaps the best studied of these is the interferon-mediated antiviral state, for which almost all viruses have evolved defence mechanisms ${ }^{82-84}$. In the case of poxviruses, the anti-interferon strategies include inhibitors of interferon induction, receptor mimics that scavenge interferon ligands, phosphatases that block the STATmediated signal-transduction pathway and inhibitors of the interferon-induced protein mediators of the antiviral state, such as protein kinase $\mathrm{R}(\mathrm{PKR})^{24,82-84}$. Indeed, there is increasing evidence that the induced interferon responses are crucial for maintaining the species barrier for some poxvirus infections. For example, myxoma virus is a rabbit-specific poxvirus that is non-permissive in primary murine fibroblasts (FIG. 4), but when interferon responses are ablated with neutralizing antibodies or drugs that prevent interferon induction, or alternatively by using cells that are derived from knockout mice deficient in components of the interferon pathway, the fibroblasts become fully permissive $e^{85}$. In fact, STAT1-deficient mice can be lethally infected by myxoma virus, whereas wild-type mice are completely resistant ${ }^{85}$. Furthermore, the interferon pathway is an important restriction determinant of myxoma virus replication in primary human fibroblasts ${ }^{86}$. In contrast to the well-studied interferon system, the mechanisms by which some of the other signalling pathways can manipulate poxvirus replication are less well understood. For example, the activation of host cell p21-activated kinase 1 (PAK1) is required for optimal replication of myxoma virus ${ }^{23}$ and extracellular signalregulated kinases 1 and 2 (ERK1,2) activation is necessary for optimal vaccinia infection ${ }^{44}$. More recently, it has been observed that many poxviruses prevent the activation of pro-inflammatory signalling cascades, 


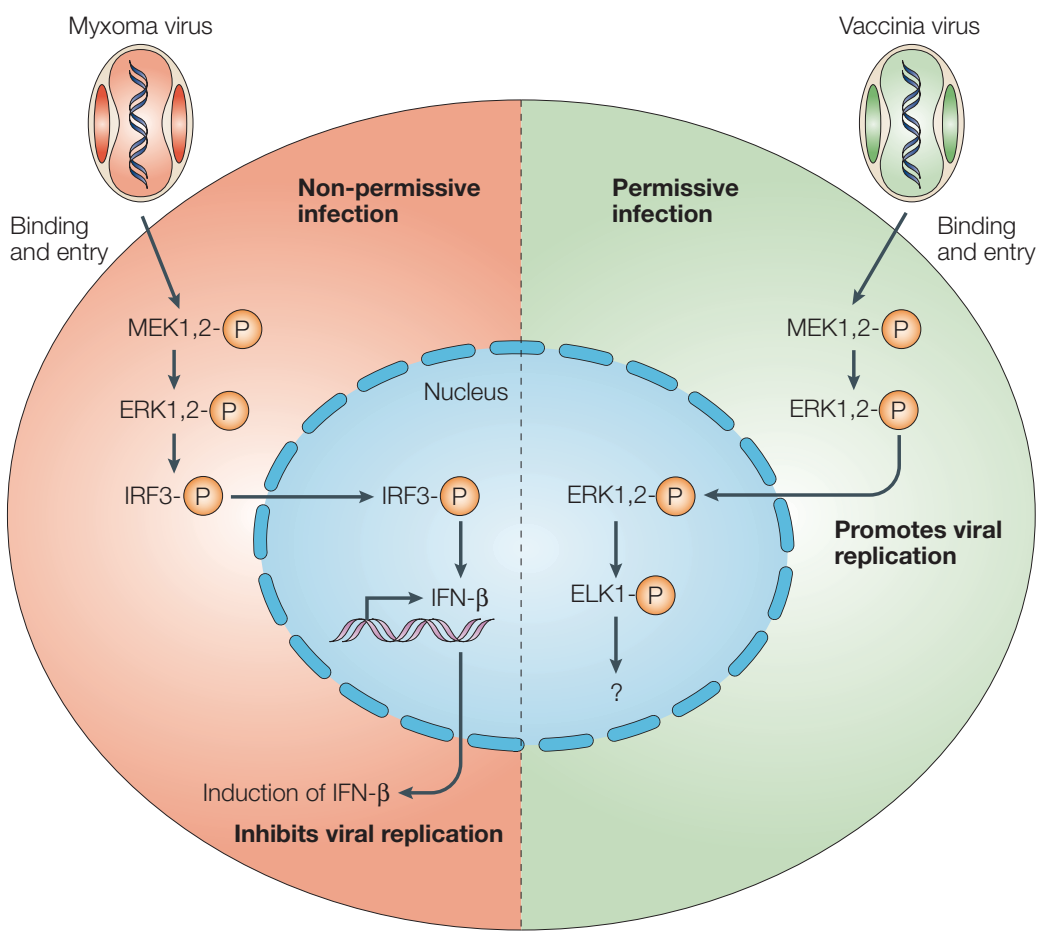

Figure 4 | Intracellular signalling events modulate poxvirus tropism. A comparison of the infection of primary murine embryo fibroblasts (pMEFs) by two poxviruses, one of which (myxoma virus) is non-permissive because it is prematurely aborted by an induced type-l interferon response, whereas the other (vaccinia virus) is fully permissive. Both infections are characterized by the induced activation of MEK1,2, which then phosphorylates extracellular signal-regulated kinase $(E R K) 1,2$. However, in the non-permissive infection by myxoma virus, phosphorylated ERK 1,2 remains in the cytoplasm where it induces the activation of interferon regulatory factor 3 (IRF3), which then migrates to the nucleus where it initiates the transcriptional upregulation of $\beta$-interferon (IFN- $\beta$ ). In the case of the permissive infection by vaccinia virus, the activated ERK 1,2 migrates to the nucleus where it activates ELK1 but does not activate IRF3 or the interferon genes. Inhibitors of ERK1,2 activation, such as U0126, render pMEFs permissive for replication of myxoma virus but, in contrast, inhibit the replication of vaccinia ${ }^{44,85,200}$.

\section{SERPIN}

Serine proteinase inhibitor, designed to bind and inhibit specific target proteinases. Poxviruses are the only viruses to express active members of this superfamily.

CATHEPSIN G

A host serine proteinase that can form inhibitory complexes with the poxviral SPI-1 serpin. such as those transduced through NF- $\kappa B$, by the concerted actions of multiple signalling inhibitors ${ }^{48,87-91}$. Finally, all poxviruses encode a wide range of inhibitors of apoptosis, a process that is frequently triggered during poxvirus infection ${ }^{92-94}$. Although this subject is too extensive to be covered in this review, one recent notable development is the appreciation that poxviruses must control the mitochondrial checkpoint of apoptotic signalling to productively infect mammalian cells ${ }^{95-97}$.

\section{Poxvirus host-range genes}

The study of viral host-range genes and the interactions of their products with host cells have provided insights into the nature of poxvirus tropism. In fact, the first host-range mutants that were described for animal viruses came from seminal work in the 1960s with rabbitpox virus mutants that failed to replicate in pig kidney cells ${ }^{98-104}$. Later, the locus that mediates this host-range phenotype was mapped to a specific virus gene that encodes the SERPIN SPI-1 (REFS 105,106). Although the exact host-cell targets of SPI-1 that mediate host range for any of the orthopoxviruses remain to be deduced ${ }^{107,108}$, the SPI-1 protein of rabbitpox virus can bind and inhibit CATHEPSIN G, which is similar in terms of substrate specificity to a classic serpin ${ }^{109}$. Interestingly, although there is evidence that SPI-1 is not a crucial determinant for poxvirus virulence in infected animals ${ }^{110,111}$, vaccinia constructs that are deleted for SPI- 1 are reported to be attenuated in mice but still remain potently immunogenic when used as vaccines ${ }^{112}$.

In addition to SPI-1, several other poxvirus hostrange genes have been identified (TABLE 3), generally by indirect methods. For example, deletion of some nonessential poxvirus genes by targeted recombination has resulted in conditional replication defects in specific cells, and these have been termed host-range genes to denote this phenotypic defect. In some cases, the classification of a host-range gene has been made only after the screening of virus gene knockout clones against panels of normally susceptible cells ${ }^{29,113}$.

As the identification of poxvirus host-range genes has been largely fortuitous, our understanding of the range of host pathways with which the protein products of these genes interact is incomplete. Nevertheless, one theme that has emerged is that the known protein products of poxvirus host-range genes are localized within infected cells, which is consistent with the need to circumvent intracellular barriers to complete the virus replication cycle (TABLE 3). The other noteworthy point is that the known host-range proteins are biochemically diverse, and no single poxvirus encodes versions of all the members. Rather, individual poxviruses have evolved their own unique subsets of host-range genes.

The first poxvirus host-range genes to be identified at the molecular level were from the vaccinia virus. Early work had indicated that certain isolates of vaccinia virus that had spontaneous gene deletions were compromised for growth in human cells ${ }^{114-116}$. Later, the K1L and C7L genes were implicated as being required for completion of the replication cycle of vaccinia virus in human cells ${ }^{113,117,118}$. Vaccinia is also unable to complete its replication cycle in Chinese hamster ovary $(\mathrm{CHO})$ cells owing to an intracellular abort that occurs shortly after virus binding and entry, at the stage of intermediate gene expression $^{119}$. The K1L/C7L defect could be rescued by another host-range gene from cowpox virus, designated $\mathrm{CHOhr}$ or $\mathrm{CP} 77$, which had been shown to be necessary for cowpox replication in $\mathrm{CHO}$ cells ${ }^{113,120,121}$. Insertion of the $\mathrm{CHOhr}$ gene into vaccinia virus or ectromelia virus allows these viruses to grow in $\mathrm{CHO}$ cells for which they are normally restricted ${ }^{122-125}$. The CHOhr gene can also rescue the host-range defects that are imparted by the loss of the K1L gene from vaccinia virus ${ }^{126,127}$. Also, whereas growth of a modified vaccinia virus that is deleted for K1L is usually restricted at the stage of early protein synthesis in rabbit kidney (RK13) cells, the expression of K1L in cells transfected with the K1L gene complements the loss of the K1L gene and allows growth of the K1L-minus vaccinia virus in RK13 cells ${ }^{128}$. K1L and CHOhr are both members of the ankyrin-repeat superfamily of proteins, which are known to be important for protein-protein interactions $^{129}$. There is some evidence that $\mathrm{CHOhr}$ affects the translation efficiency of viral intermediate proteins at the level of eukaryotic-translation initiation 


\begin{tabular}{lll}
\hline Table 3 | Poxvirus host-range genes & \\
\hline Myxoma virus & Protein type & $\begin{array}{l}\text { Cultured cells with defects } \\
\text { in virus tropism* }\end{array}$ \\
\hline M-T5 & Ankyrin repeats & Rabbit T cells, human tumour cells \\
M-T2 & TNF receptor & Rabbit T cells \\
\hline M-T4 & ER-localized & Rabbit T cells \\
M11L & Mitochondrial & Rabbit T cells \\
\hline Vaccinia virus & PKR inhibition & HeLa cells, CEF (MVA-E3L-) \\
\hline E3L & dsRNA-BP & BHK cells \\
\hline K3L & Serpin & Human keratinocytes, A549 \\
\hline B22R/SPI-1 & Cytoplasmic & Hamster Dede cells \\
\hline C7L ${ }^{\ddagger}$ & Ankyrin-repeats & RK13 cells \\
\hline K1L ${ }^{\ddagger}$ & & \\
\hline Rabbitpox virus & Serpin & PK15 cells, A549 \\
\hline SPI-1 & & \\
\hline Ectromelia virus & & Mouse macrophages \\
\hline p28 & E3-ubiquitin ligase & \\
\hline Cowpox virus & & W-C9L grows on CHO cells; \\
\hline C9L/CP77/CHOhr & Ankyrin repeats & W-K1L/C9L grows on RK13 cells \\
\hline
\end{tabular}

*Host-range defect is specifically exhibited by viral gene knockout constructs or viral recombinants

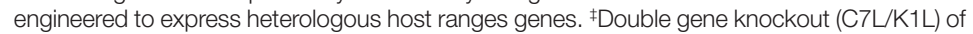
vaccinia virus (VV) unable to replicate in PK1 cells or most human cells. BHK, baby hamster kidney; $\mathrm{CEF}$, chicken embryo fibroblasts; $\mathrm{CHO}$, Chinese hamster ovary; dsRNA-BP, double-stranded-RNA binding protein; ER, endoplasmic reticulum; MVA, modified vaccinia Ankara; PK15, pig kidney 15; PKR, protein kinase R; RK13, rabbit kidney 13; SPI-1, serine proteinase inhibitor 1; TNF, tumournecrosis factor. type I interferon by blocking the activation of interferon regulatory factor 3 (IRF3) and IRF7 (REF. 138). Vaccinia virus constructs that lack E3L are restricted for replication in many cells ${ }^{139,140}$, whereas K3L-minus vaccinia infection is abortive specifically in baby hamster kidney (BHK) cells ${ }^{137,140}$. There is some evidence that the precise levels of dsRNA and PKR that are induced in infected cells determine the hierarchy of importance of E3L and $\mathrm{K} 3 \mathrm{~L}$ in host-cell tropism ${ }^{137}$. This ability of poxviruses to counteract the inhibitory properties of interferon is linked with the inhibition of apoptosis, and can directly affect the replication and antigen-presenting potential of non-replicating poxvirus vaccines ${ }^{141,142}$.

The most recent example of a poxvirus host-range protein for which a specific biochemical function has been ascribed is the p28-RING zinc-finger protein of ectromelia virus (EV-p28). EV-p28 is essential for virulence in mice and deletion of the EV-p28 gene renders ectromelia virus unable to productively replicate in mouse macrophages ${ }^{143,144}$. The EV-p28 protein functions as an E3-ubiquitin ligase ${ }^{145,146}$, so presumably the inability of the EV-p28-minus virus to direct substrate proteins for ubiquitination and degradation contributes to the non-permissive phenotype in infected macrophages, but the relevant host targets remain to be identified.

\section{Tropism for tissue and organism}

When poxviruses from a long-term evolutionary host cross into a novel species, marked differences in pathogenesis can sometimes occur. For example, the rabbitspecific myxoma virus is relatively non-pathogenic in its evolutionary host, the Sylvilagus (brush) rabbit, but is almost $100 \%$ fatal in the Oryctolagus (European) rabbit $^{147}$. On the other hand, some poxviruses, such as variola virus, are thought to have never spontaneously crossed into another host species, but can be experimentally manipulated to cause disease if injected intravenously at high dosages into particular primate hosts ${ }^{148,149}$. The study of poxvirus pathogenesis, and particularly the host determinants that influence virus replication and dissemination in diverse tissues, is in its infancy ${ }^{10}$. In fact, knowledge about the genetic loci that control intrinsic immunity to most viral infections is still limited, but there have been recent advances in the identification of specific host-restriction factors, particularly for infection by retroviruses ${ }^{150}$. At present, the ectromelia virus, which causes mousepox, is the only poxvirus for which there is information on the host genetic loci that influence susceptibility to infection ${ }^{151}$.

The study of mouse strains that exhibit variable resistance or susceptibility to infection by ectromelia virus has revealed important clues about how host genetics influences poxvirus pathogenesis and host range. Ectromelia virus is highly infectious in all strains of laboratory mice, but induces lethal disease only in strains with particular genetic backgrounds (for example, $\mathrm{CBA}, \mathrm{A} / \mathrm{J}, \mathrm{BALB} / \mathrm{c}$ or DBA/2) and is readily cleared in other strains (for example, C57/BL or AKR), which are considered to be resistant but can be silent carriers of mousepox ${ }^{151}$. Resistant mouse strains are characterized 
by a more integrated immune response to ectromelia virus, which includes robust early innate immune responses (particularly interferon induction, macrophage activation and natural killer (NK) responses), as well as efficient adaptive responses (mediated by $\mathrm{CD} 8^{+}$cytotoxic $\mathrm{T}$ cells, $\mathrm{CD} 4^{+} \mathrm{T}$-helper $\left(\mathrm{T}_{\mathrm{H}}\right)$ cells and antibodies $)^{152-154}$. Breeding experiments indicate that resistance is dominant over susceptibility, and four genes that confer resistance to mousepox (designated Rmp1-4) have been mapped ${ }^{155-160}$. Furthermore, other genetic loci that affect immune responses and susceptibility to ectromelia continue to be discovered in mice ${ }^{161-163}$. In general, the polarization of $\mathrm{T}_{\mathrm{H}}$ cells of the host immune response is believed to be crucial in determining whether a given poxvirus infection will be subclinical and resolve, or will progress to systemic disease ${ }^{164-166}$. Specifically, the ability of an infected immunologically naive host to mount a $\mathrm{T}_{\mathrm{H}}$-POLARIZED IMMUNE RESPONSE is regarded as crucial for the control of poxvirus infection and for recovery ${ }^{164,167}$. This point was dramatically emphasized when it was observed that a recombinant ectromelia virus that expresses interleukin 4 , a potent $\mathrm{T}_{\mathrm{H}} 2$ cytokine, was lethal in normally non-suceptible mice ${ }^{168}$.

\section{Host-restricted poxvirus vectors}

In addition to the need to better understand the factors that control disease pathogenesis, host range and zoonoses, there are practical issues relating to the potential manipulation of poxvirus tropism. The most important of these is the development of host-restricted poxvirus vectors as safe platforms for vaccines or gene delivery ${ }^{169-172}$. The vaccinia virus strains that were used to eradicate smallpox were effective and highly immunogenic, but caused high rates of post-vaccination medical complications that are now considered excessive by modern safety standards ${ }^{173,174}$. At present, there are more people with some form of immune compromise than during the smallpox eradication era up to the mid1970s, and so efforts have been directed towards the development of poxvirus-based vectors that are restricted for replication in humans.

Non-replicating poxvirus vaccines. Generally, these efforts involve two related strategies - the isolation of vaccinia variants (for example, MVA, LC16m8 or NYVAC) that show reduced virulence, or the development of poxvirus platforms such as canarypox (ALVAC) and fowlpox (TROVAC) that are naturally non-permissive for human cells. There is increasing evidence that such non-replicating vaccines are safer than the original vaccinia strains and yet are still comparably immunogenic ${ }^{130,175-180}$.

The subject of non-replicating poxvirus vector development is too extensive for this review, but a few of the defining features can be summarized using MVA as the prototypical example (FIG. 5). MVA was derived from a Turkish smallpox vaccine strain (Ankara) that, after more than 500 passages in chicken cells, became defective for replication in human cells and avirulent in test animals ${ }^{181}$. From 1968-1980, MVA was inoculated into more than 100,000 individuals in Germany with no reported secondary complications and it is now considered to be a suitable platform for the next generation of safer smallpox vaccines and recombinant poxvirus vectors ${ }^{182}$. Genomic mapping and sequencing studies have revealed that MVA lost nearly $30 \mathrm{~kb}$ of genomic information during its extended passage in chicken cells and has multiple deletions and mutations compared with the parental strain ${ }^{183}$. Many of these genetic alterations were in host-response genes, and it is assumed that these deletions render MVA unable to complete its replication cycle in human cells ${ }^{184,185}$. Importantly, MVA was shown to retain a copy of the E3L host-range gene, and a targeted E3L deletion rendered the virus unable to replicate even in chicken embryo fibroblasts ${ }^{142}$. To facilitate the generation of MVA-based recombinant vectors, another host-range gene that is missing from MVA, K1L, was exploited in targeted insertion vectors as a selection marker to allow the replication of MVA-K1L-expressing virus in normally non-permissive rabbit RK13 cells ${ }^{186-188}$. Another technical advantage of MVA over other vaccinia strains is that the loss of immunomodulatory genes has caused the virus to induce excessive activation of infected human dendritic cells, which possibly explains its enhanced immunogenicity ${ }^{75}$. Future advances in the exploitation of MVA and other human-restricted poxvirus vaccine vectors will probably focus on modifying the immune responses of the infected host to specifically optimize presentation of key immunogenic epitopes by the non-replicating vector.

Poxviruses as oncolytic vectors. In the future, hostrestricted poxviruses might be exploited as therapeutic oncolytic viruses. In addition to the use of poxvirus vectors to deliver cancer immunotherapeutics, or to provide vaccine vehicles for tumour-specific cellular epitopes $^{169,171,189}$, a wide range of viruses that exhibit increased replication or pronounced cytopathology in transformed cells have been explored as potential therapeutic agents to target and kill cancer cells ${ }^{190-192}$. For example, attempts have been made to harness vaccinia virus as an oncolytic vector to specifically target cancer cells ${ }^{193,194}$. Although wild-type vaccinia virus shows no specific predilection to bind and infect transformed cells, several studies have shown increased viral replication levels in tumours ${ }^{195}$. Furthermore, a vaccinia virus with deletions of the genes that encode thymidine kinase and the vaccinia growth factor showed preferential replication in rapidly growing tumour cells while becoming attenuated for overall virulence ${ }^{196}$. An important technical advantage of poxvirus-based vectors is the ability to insert multiple genes to increase the therapeutic potential of the virus or to assist in its visualization ${ }^{195,197}$. Although attempts have been made to target vaccinia binding to specific cell types by engineering virion surface proteins that mediate host cell binding ${ }^{198}$, such attempts have never circumvented the ability of the virus to bind to and enter mammalian cells promiscuously. It is likely that future use of oncolytic poxviruses will involve 


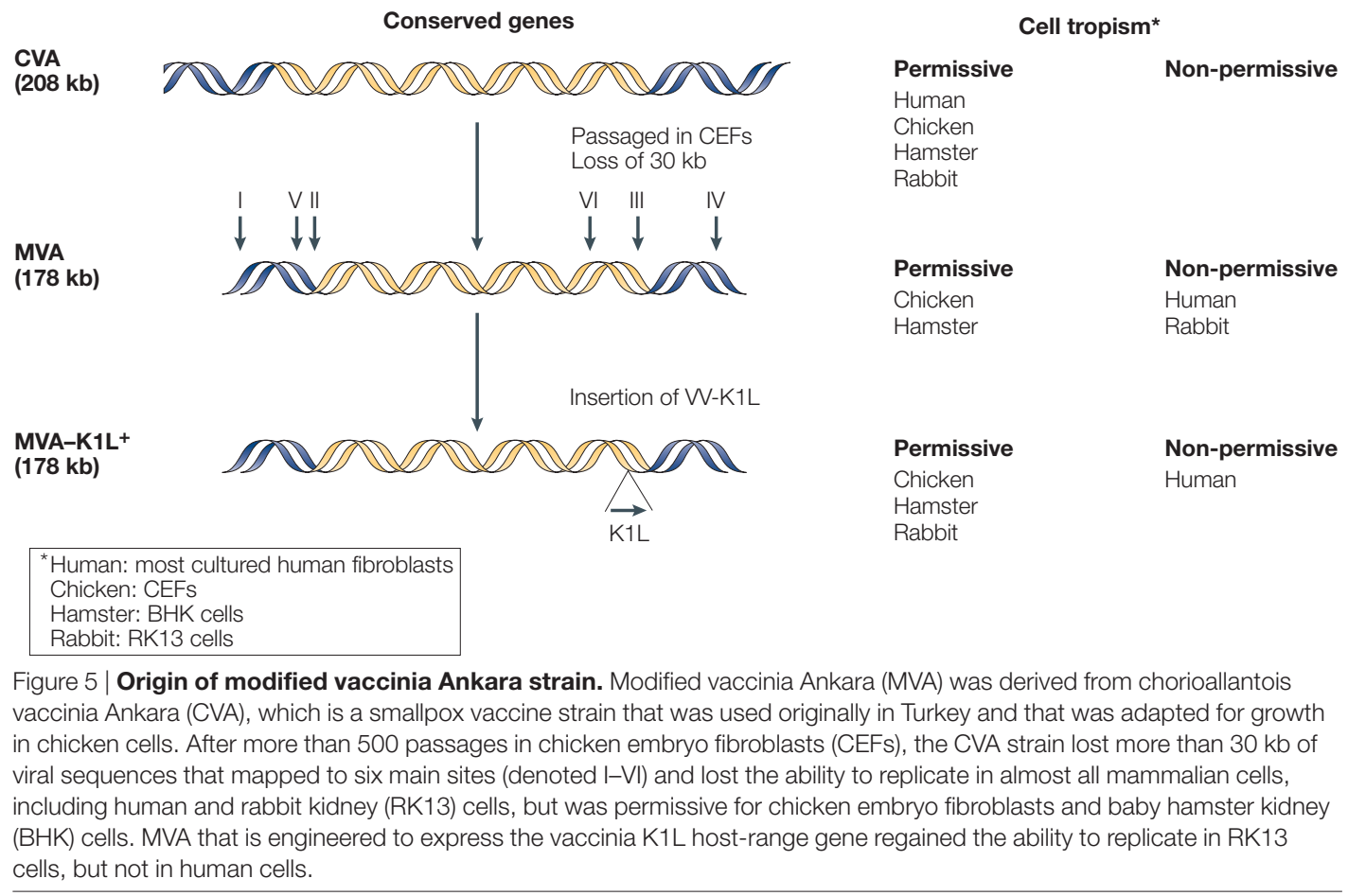

exploiting the signalling differences between normal and transformed cells so that the oncolytic virus will spread efficiently in tumour cells, as well as deliver therapeutic transgenes to assist in tumour killing and immunotherapy. In this regard, it should be noted that some poxviruses, such as myxoma virus, that are normally restricted to non-human cells, can nevertheless replicate robustly in human tumour cells ${ }^{18}$, and provide additional platforms with which to explore poxvirus-based oncolytic therapies.

\section{Concluding remarks}

It has been a quarter of a century since smallpox was eradicated by the WHO vaccination programme. Although the potential re-emergence of smallpox as a consequence of deliberate bioterrorism has been the subject of intense speculation, the appearance of any pathogenic poxvirus that spreads efficiently from human-to-human would be considered an immediate public health crisis. The 2003 human monkeypox outbreak in the United States illustrates how vulnerable the human population is to the emergence and reemergence of viral pathogens from unsuspected sources. In the case of poxviruses, we know little about the features that govern the species tropism of poxvirus-host relationships, or the hurdles that need to be overcome to initiate zoonotic poxvirus infections in non-evolutionary hosts. The best available evidence indicates that poxviruses bind to and enter mammalian cells promiscuously, but their ability to complete the complex cytoplasmic replication cycle that is needed to generate progeny virus, and then to spread successfully to a new host, can vary markedly between cells of different lineages and host species.
On the basis of our current knowledge, all the main determinants of poxvirus tropism at the cellular level are intracellular events that take place downstream of virus binding and entry. Although signals from specific sentinel host-cell receptors can probably regulate subsequent poxvirus replication, it seems that poxviruses do not require specific host-cell receptors for virus adsorption and fusion events, for the efficient internalization of the virus core structure or for the initiation of early transcription. Rather, the main features that functionally regulate subsequent events in the infected cell are the requirement for various trans-acting factors from the host cell and the ability to inhibit diverse cellular antiviral responses such as apoptosis and the interferon pathway. Also, the ultimate outcome of a given infection is potently influenced by the unique portfolio of immunomodulatory and host-range genes that give each poxvirus unique properties of host range, pathogenesis and the potential for host-to-host spread.

As more information is gathered about the molecular basis for tropism determinants of poxviruses, it is likely that new strategies will be uncovered to experimentally manipulate the natural species barriers that regulate zoonotic infections. This knowledge will facilitate the engineering of poxviruses as safer vectors for vaccines and gene therapy, and as tissue-targeted oncolytic viruses to treat human neoplasms. However, the sobering conclusion remains that even if the final stocks of variola virus are destroyed, the potential for the emergence of other poxvirus-derived human pathogens remains. Hopefully, as the general principles that govern poxvirus tropism and host range are better understood, we will also be better prepared to respond to other zoonotic virus infections. 
1. Morens, D. M., Folkers, G. K. \& Fauci, A. S. The challenge of emerging and re-emerging infectious diseases. Nature $\mathbf{4 3 0}$ 242-249 (2004)

2. Finlay, B. B., See, R. H. \& Brunham, R. C. Rapid response research to emerging infectious diseases: lessons from SARS. Nature 2, 602-607 (2004)

3. Smith, G. L. \& McFadden, G. Smallpox: anything to declare? Nature Rev. Immunol. 2, 521-528 (2002).

4. Tucker, J. B. Scourge: The Once and Future Threat of Smallpox (Atlantic Monthly Press, New York, 2001).

5. Alibek, K. Biohazard (Random House, New York, 1999).

6. Harrison, S. C. et al. Discovery of antivirals against smallpox Proc. Natl Acad. Sci. USA 101, 11178-11192 (2004).

7. Bray, M. \& Roy, C. J. Antiviral prophylaxis of smallpox. J. Antimicrob. Chemother. 54, 1-5 (2004).

8. Lewis-Jones, S. Zoonotic poxvirus infection in humans. Curr. Opin. Infect. Dis. 17, 81-89 (2004).

A useful summary of the poxviruses that can zoonotically infect man, which indicates which of these infections are clinically important.

9. Frey, S. E. \& Belshe, R. B. Poxvirus zoonoses - putting pocks into context. N. Engl. J. Med. 350, 324-327 (2004)

10. Esposito, J. J. \& Fenner, F. in Fields Virology 4th edn (eds Knipe, D. M. \& Howley, P. M.) 2885-2921 (Lippincott Williams \& Wilkins, Philadelphia, 2001).

11. Reed, K. D. et al. The detection of monkeypox in humans in the western Hemisphere. N. Engl. J. Med. 350, 342-350 (2004)

12. Di Giulio, D. B. \& Eckburg, P. B. Human monkeypox: an emerging zoonosis. Lancet Infect. Dis. 4, 15-25 (2004).

13. Hutin, Y. J. F. et al. Outbreak of human monkeypox Democratic Republic of Congo, 1996-1997. Emerg. Infect. Dis. 7, 434-438 (2001).

14. Meyer, H. et al. Outbreaks of disease suspected of being due to human monkeypox virus infection in the Democratic Republic of Congo in 2001. J. Clin. Microbiol. 40 2919-2921 (2002)

15. Breman, J. G. in Emerging Infections (eds Schield, W. M., Craig, W. A. \& Hughes, J. M.) 45-67 (ASM Press, Washington DC, 2000).

16. Guarner, J. et al. Monkeypox transmission and pathogenesis in prairie dogs. Emerg. Infect. Dis. 10 426-431 (2004)

17. Fenner, F. \& Ratcliffe, F. N. Myxomatosis (Cambridge Univ. Press, UK, 1965)

18. Sypula, J., Wang, F., Ma, Y., Bell, J. \& McFadden, G. Myxoma virus tropism in human tumor cells. Gene Ther. Mol. Biol. 8, 103-114 (2004)

19. Dimitrov, D. S. Virus entry: molecular mechanisms and biomedical applications. Nature Rev. Microbiol. 2, 109-122 (2004).

20. Smith, A. E. \& Helenius, A. How viruses enter animal cells. Science 304, 237-241 (2004)

21. Lalani, A. S. et al. Use of chemokine receptors by poxviruses Science 286, 1968-1971 (1999).

22. Eppstein, D. A. et al. Epidermal growth factor receptor occupancy inhibits vaccinia virus infection. Nature $\mathbf{3 1 8}$ 663-665 (1985)

23. Johnston, J. B. et al. Role of the serine-threonine kinase PAK-1 in myxoma virus replication. J. Virol. 77, 5877-5888. (2003)

24. Seet, B. T. et al. Poxviruses and immune evasion. Annu. Rev. Immunol. 21, 377-423 (2003). Summarizes the known immunomodulator and host-range gene families found in poxviruses, and documents the members that can be encoded by different poxviruses.

25. Moss, B. in Fields Virology (eds Knipe, D. M. \& Howley, P. M.) 2849-2883 (Lippincott Williams \& Wilkins, Philadelphia, 2001)

26. Upton, C., Slack, S., Hunter, A. L., Ehlers, A. \& Roper, R. L. Poxvirus orthologous clusters: toward defining the minimum essential poxvirus genome. J. Virol. $\mathbf{7 7}$ 7590-7600 (2003)

27. McLysaght, A., Baldi, P. F. \& Gaut, B. S. Extensive gene gain associated with adaptive evoluton of poxviruses. Proc. Natl Acad. Sci. USA 100, 15655-15660 (2003).

28. Gubser, C., Hue, S., Kellam, P. \& Smith, G. L. Poxvirus genomes: a phylogenetic analysis. J. Gen. Virol. $\mathbf{8 5}$, 105-117 (2004)

29. Johnston, J. B. \& McFadden, G. Technical knockout: understanding poxvirus pathogenesis by selectively deleting viral immunomodulatory genes. Cell. Microbiol. 9, 695-705 (2004).

30. Turner, P. C. \& Moyer, R. W. Poxvirus immune modulators: functional insights from animal models. Virus Res. 88, 35-53 (2002)

31. Smith, S. A. \& Kotwal, G. J. Immune response to poxvirus infections in various animals. Crit. Rev. Microbiol. 28 149-185 (2002)
32. Smith, G. L., Vanderplasschen, A. \& Law, M. The formation and function of extracellular enveloped vaccinia virus. J. Gen. Virol. 83, 2915-2931 (2002)

33. Vanderplasschen, A., Hollinshead, M. \& Smith, G. L. Intracellular and extracellular vaccinia virions enter cells by different mechanisms. J. Gen. Virol. 79, 877-887 (1998).

34. Vanderplasschen, A. \& Smith, G. L. A novel virus-binding assay using confocal microscopy: Demonstration that the intracellular and extracellular vaccinia virions bind to different cellular receptors. J. Virol. 71, 4032-4041 (1997).

35. Locker, J. K. et al. Entry of the two infectious forms of vaccinia virus at the plasma membane is signalingdependent for the IMV but not the EEV. Mol. Biol. Cell 11, 2497-2511 (2000).

36. Blasco, R., Sisler, J. R. \& Moss, B. Dissociation of progeny vaccinia virus from the cell membrane is regulated by a viral envelope glycoprotein - effect of a point mutation in the lectin homology domain of the A34R gene. J. Virol. $\mathbf{6 7}$, 3319-3325 (1993).

37. Lin, C. L., Chung, C. S., Heine, H. G. \& Chang, W. Vaccinia virus envelope H3L protein binds to cell surface heparan sulfate and is important for intracellular mature virion morphogenesis and virus infection in vitro and in vivo. J. Virol. 74, 3353-3365 (2000).

38. Hsiao, J.-C., Chung, C.-S. \& Chang, W. Vaccinia envelope D8L protein binds to cell surface chondroitin sulfate and mediates intracellular mature virions adsorption to cells. J. Virol. 73, 8750-8761 (1999).

39. Chung, C.-S., Hsiao, J.-C., Chang, Y.-S. \& Chang, W. A27L protein mediates vaccinia virus interaction with cell surface heparan sulfate. J. Virol. 72, 1577-1585 (1998).

40. Hsiao, J.-C., Chung, C.-S. \& Chang, W. Cell surface proteoglycans are necessary for A27L protein-mediated cell fusion: identification of the $\mathrm{N}$-terminal region of $\mathrm{A} 27 \mathrm{~L}$ protein as the glycosaminoglycan-binding domain. J. Virol. 72, 8374-8379 (1998)

41. Senkevich, T. G., Ward, B. M. \& Moss, B. Vaccinia virus entry into cells is dependent on a virion surface protein encoded by the A28L gene. J. Virol. 78, 2357-2366 (2004).

Describes the first poxviral protein (A28 of vaccinia virus) shown to be critical for the fusion/entry of poxviruses into mammalian cells.

42. Masters, J. et al. Poxvirus infection rapidly activates tyrosine kinase signal transduction. J. Biol. Chem. 276 48371-48375 (2001).

43. de Magalhaes, J. C. et al. A mitogenic signal triggered at an early stage of vaccinia virus infection - implication of MEK/ERK and protein kinase in a virus multiplication. J. Biol. Chem. 276, 38353-38360 (2001).

44. Andrade, A. A. et al. The vaccinia virus-stimulated mitogenactivated protein kinase (MAPK) pathway is required for virus multiplication. Biochem. J. 381, 437-446 (2004).

45. Greber, U. F. Signaling in viral entry. Cell. Mol. Life Sci. $\mathbf{5 9}$ 608-626 (2002).

46. Boehme, K. W. \& Compton, T. Innate sensing of viruses by Toll-like receptors. J. Virol. 78, 7867-7873 (2004).

47. Bowie, A. et al. A46R and A52R from vaccinia virus are antagonists of host IL-1 and Toll-like receptor signaling. Proc. Natl Acad. Sci. USA 97, 10162-10167 (2000).

48. Harte, M. T. et al. The poxvirus protein A52R targets Toll-like receptor signaling complexes to suppress host defense. J. Exp. Med. 197, 343-351 (2003).

49. Broyles, S. S. Vaccinia virus transcripton. J. Gen. Virol. 84 2293-2303 (2003).

50. Rosales, R., Sutter, G. \& Moss, B. A cellular factor is required for transcription of vaccinia viral intermediatestage genes. Proc. Natl Acad. Sci. USA 91, 3794-3798 (1994).

51. Rosales, R., Harris, N., Ahn, B. Y. \& Moss, B. Purification and identification of a vaccinia virus-encoded intermediate stage promoter-specific transcription factor that has homology to eukaryotic transcription factor SII (TFIIS) and an additional role as a viral RNA polymerase subunit. J. Biol. Chem. $\mathbf{2 6 9}$ 14260-14267 (1994)

52. Sanz, P. \& Moss, B. A new vaccinia virus intermediate transcription factor. J. Virol. 72, 6880-6883 (1998).

53. Gunasinghe, S. K., Hubbs, A. E. \& Wright, C. F. A vaccinia virus late transcription factor with biochemical and molecular identity to a human cellular protein. J. Biol. Chem. 273, 27524-27530 (1998).

54. Wright, C. F., Hubbs, A. E., Gunasinghe, S. K. \& Oswald, B. W. A vaccinia virus late transcription factor copurifies with a facto that binds to a viral late promoter and is complemented by extracts from uninfected HeLa cells. J. Virol. 72, 1446-1451 (1998).

55. Broyles, S. S., Liu, X., Zhu, M. \& Kremer, M. Transcription factor $Y Y 1$ is a vaccinia virus late promoter activator. J. Bio. Chem. 274, 35662-35667 (1999).
56. Katsafanas, G. C. \& Moss, B. Vaccinia virus intermediate stage transcription is complemented by Ras-GTPaseactivating protein $\mathrm{SH} 3$ domain-binding protein (G3BP) and cytoplasmic activation/proliferation-associated protein (p137) individually or as a heterodimer. J. Biol. Chem. 279, 52210-52217 (2004)

57. Smith, G. L., Murphy, B. J. \& Law, M. Vaccinia virus motility. Annu. Rev. Microbiol. 57, 323-342 (2003).

58. Smith, G. L. \& Law, M. The exit of vaccinia virus from infected cells. Virus Res. 106, 189-197 (2004).

59. Katz, E., Ward, B. M., Weisberg, A. S. \& Moss, B. Mutations in the vaccinia virus $A 33 R$ and $B 5 R$ envelope proteins that enhance release of extracellular virions and eliminate formation of actin-containing microvilli without preventing tyrosine phosphorylation of the A36R protein. J. Virol. $\mathbf{7 7}$, 12266-12275 (2003)

60. Newsome, T. P., Scaplehorn, N. \& Way, M. Src mediates a switch from microtubule- to actin-based motility of vaccinia virus. Science 306, 124-129 (2004).

61. Frischknecht, F. et al. Actin-based motility of vaccinia virus mimics receptor tyrosine kinase signalling. Nature $\mathbf{4 0 1}$, 926-929 (1999).

62. McFadden, G., Pace, W. E., Purres, J. \& Dales, S. Biogenesis of poxvirus: transitory expression of Molluscum contagiosum early functions. Virology 94, 297-313 (1979).

63. Li, Y., Yuan, S. \& Moyer, R. W. The non-permissive infection of insect (Gypsy Moth) Ld-652 cells by vaccinia virus. Virology 248, 74-82 (1998).

64. Wali, A. \& Strayer, D. S. Regulation of p53 gene expression by a poxviral transcription factor. Virology 224, 63-72 (1996).

65. Wali, A. \& Strayer, D. S. Infection with vaccinia virus alters regulation of cell cycle progression. DNA Cell Biol. 18, 837-843 (1999).

66. Santos, C. R., Vega, F. M., Blanco, S., Barcia, R. \& Lazo, P. A The vaccinia virus B1R kinase induces p53 downregulation by an Mdm2-dependent mechanism. Virology 328, 254-265 (2004).

67. Guerra, S. et al. Cellular gene expression survey of vaccinia virus infection of human HeLa cells. J. Virol. 77, 6493-6506 (2003).

68. Guerra, S. et al. Microarray analysis reveals characteristic changes of host cell gene expression in response to attenuated modified vaccinia virus Ankara infection of human HeLa cells. J. Virol. 78, 5820-5834 (2004)

69. Senkevich, T. G. et al. Genome sequence of a human tumorigenic poxvirus: prediction of specific host responseevasion genes. Science 273, 813-816 (1996).

70. Senkevich, T. G., Koonin, E. V., Bugert, J. J., Darai, G. \& Moss, B. The genome of molluscum contagiosum virus: analysis and comparison with other poxviruses. Virology $\mathbf{2 3 3}$ 19-42 (1997).

71. Brown, M. et al. Antigen gene transfer to cultured human dendritic cells using recombinant avipoxvirus vectors. Cancer Gene Ther. 6, 238-245 (1999).

72. Brown, M. et al. Dendritic cells infected with recombinant fowlpox virus vectors are potent and long-acting stimulators of transgene-specific class 1 restricted T lymphocyte activity. Gene Ther. 7, 1680-1689 (2001)

73. Engelmayer, J. et al. Mature dendritic cells infected with canarypox virus elicit strong anti-human immunodeficiency virus $\mathrm{CD}^{+}$and $\mathrm{CD} 4^{+} \mathrm{T}$-cell responses from chronically infected individuals. J. Virol. 75, 2142-2153 (2001).

74. Ignatius, R. et al. Canarypox virus-induced maturation of dendritic cells is mediated by apoptotic cell death and tumor necrosis factor- $\alpha$ secretion. J. Virol. 74, 11329-11338 (2000).

75. Drillien, R., Spehner, D. \& Hanau, D. Modified vaccinia virus Ankara induces moderate activation of human dendritic cells. J. Gen. Virol. 85, 2167-2175 (2004).

76. Hurnlova, Z., Vokurka, M., Esteban, M. \& Melkova, Z. Vaccinia virus induces apoptosis of infected macrophages. J. Gen. Virol. 83, 2821-2832 (2002)

77. Jenne, L., Hauser, C., Arrighi, J. F., Saurat, J. H. \& Hugin, A. W. Poxvirus as a vector to transduce human dendritic cells fo immunotherapy: abortive infection but reduced APC function. Gene Ther. 7, 1575-1583 (2000).

78. Bronte, V. et al. Antigen expression by dendritic cells correlates with the therapeutic effectiveness of a model recombinant poxvirus tumor vaccine. Immunology $\mathbf{9 4}$ 3183-3188 (1997)

79. Engelmayer, J. et al. Vaccinia virus inhibits the maturation of human dendritic cells: a novel mechanism of immune evasion. J. Immunol. 163, 6762-6768 (1999).

80. Drillien, R., Spehner, D., Bohbot, A. \& Hanau, D. Vaccinia virus-related events and phenotypic changes after infection of dendritic cells derived from human monocytes. Virology $\mathbf{2 6 8}$ 471-481 (2000).

81. Hung, J.-J., Chung, C.-S. \& Chang, W. Molecular chaperone Hsp90 is important for vaccinia virus growth in cells. J. Virol. 76, 1379-1390 (2002) 
One of the few studies to identify a host factor, in this case $\mathrm{Hsp60}$, that is specifically required for efficient completion of the viral morphogenic pathway.

82. Sen, G. C. Viruses and interferon. Annu. Rev. Microbiol. 55 255-281 (2001).

83. Samuel, C. E. Antiviral actions of interferons. Clin. Microbio Rev. 14, 778-809 (2001)

84. Katze, M. G., He, Y. \& Gale, M. Jr. Viruses and interferon: a fight for supremacy. Nature Rev. Immunol. 2, 675-687 (2002).

85. Wang, F. et al. Disruption of ERK 1/2 MAP kinase-dependent induction of type I interferon breaks myxoma virus species barrier. Nature Immunol. 5, 1266-1274 (2004). The first demonstration that the host species barrier for any poxvirus can be manipulated at the level of signal transduction, and shows that the induction of interferon by the infecting poxvirus is a crucia determinant of myxoma virus tropism.

86. Johnston, J. B., Nazarian, S. H., Natale, R. \& McFadden, G. Myxoma virus infection of primary human fibroblasts varies with cellular age and is regulated by host interferon responses. Virology (in the press).

87. Ole, K. L. \& Pickup, D. J. Cowpox virus and other members of the orthopoxvirus genus interfere with the regulation of NF- $\mathrm{KB}$ activation. Virology 288, 175-187 (2001)

88. Gil, J., Rullas, J., Alcami, J. \& Estaban, M. MC159L protein from the poxvirus molluscum contagiosum virus inhibits NF-K B activation and apoptosis induced by PKR. J. Gen. Virol. 82, 3027-3034 (2001)

89. Shisler, J. L. \& Jin, X.-L. The vaccinia virus K1L gene product inhibits host NF-KB $\alpha$ degradation. J. Virol. 78, 3553-3560 (2004).

Demonstrates that a poxvirus host-range factor, $\mathrm{K} 1 \mathrm{~L}$ of vaccinia, can affect the activation of an important antiviral pathway - that of NF-KB.

90. DiPerna, G. et al. Poxvirus protein N1L targets the $\mathrm{I}-\mathrm{kB}$ kinase complex, inhibits signaling to NF-KB and IRF3 signaling by Toll-like receptors. J. Biol. Chem. 279 , 36570-36578 (2004).

Shows that a poxviral protein, N1L of vaccinia, might target the same host pathway as the host-range facto K1L, indicating that some host pathways are multiply targeted by poxviruses and that it is the summation of these modulations that affects tropism and host range.

91. Camus-Bouclainville, C. et al. A virulence factor of myxoma virus colocalizes with NF-KB in the nucleus and interferes with inflammation. J. Virol. 78, 2510-2516 (2004).

92. Everett, H. \& McFadden, G. Poxviruses and apoptosis: a time to die. Curr. Opin. Microbiol. 5, 395-402 (2002).

93. Shisler, J. L. \& Moss, B. Immunology 102 at poxvirus U: avoiding apoptosis. Semin. Immunol. 13, 67-72 (2001).

94. Barry, M. Wasilenko, S. T., Stewart, T. L. \& Taylor, J. M. Apoptosis regulator genes encoded by poxviruses. Prog. Mol. Subcell. Biol. 36, 19-37 (2004).

95. Everett, H. et al. The myxoma poxvirus protein, M11L, prevents apoptosis by direct interaction with the mitochondrial permeability transition pore. J. Exp. Med. 196, 1127-1139. (2002)

96. Wasilenko, S. T., Stewart, T. L., Meyers, A. F. \& Barry, M. Vaccinia virus encodes a previously uncharacterized mitochondrial-associated inhibitor of apoptosis. Proc. Nat Acad. Sci. USA 100, 14345-14350 (2003).

97. Wang, G. et al. Myxoma virus M11L prevents apoptosis through constitutive interaction with Bak. J. Virol. 78, 7097-7111 (2004).

98. Fenner, F. \& Sambrook, J. F. Conditional lethal mutants of rabbitpox virus II. Mutants (p) that fail to multiply in PK-2a cells. Virology 28, 600-609 (1966).

99. Sambrook, J. F., Padgett, B. L. \& Tomkins, J. K. N. Conditional lethal mutants of rabbitpox virus I Isolation of host cell-dependent and temperature-dependent mutants. Virology 28, 592-599 (1966).

100. Gemmell, A. \& Fenner, F. Genetic studies with mammalian poxviruses. III. White $(u)$ mutants of rabbitpox virus. Virolog 11, 219-235 (1960).

101. McClain, M. E. The host range and plaque morphology of rabbitpox virus $(\mathrm{RP} \mu+)$ and its $\mu$ mutants on chick fibroblast, PK-2a, and L929 cells. Aust. J. Exp. Biol. Med. Sci. 43, 31-44 (1965)

102. McClain, M. E. \& Greenland, R. H. Recombination between rabbitpox virus mutants in permissive and nonpermissive cells. Virology 25, 516-522 (1965).

103. Lake, J. R. \& Cooper, P. D. Deletions of the terminal sequences in the genome of the white pock $(\mu)$ and host restricted $(\rho)$ mutants of rabbitpox virus. J. Gen. Virol. $\mathbf{4 8}$ 135-147 (1980).

104. Moyer, R. W., Brown, G. D. \& Graves, R. L. The white pock mutants of rabbit poxvirus. II. The early white pock (mu) host range (hr) mutants of rabbit poxvirus uncouple transcription and translation in nonpermissive cells. Virology 106, 234-249 (1980)
105. Ali, A. N., Turner, P. C., Brooks, M. A. \& Moyer, R. W. The SPI-1 gene of rabbitpox virus determines host range and is required for hemorrhagic pock formation. Virology $\mathbf{2 0 2}$, 305-314 (1994)

106. Brooks, M. A., Ali, A. N., Turner, P. C. \& Moyer, R. W. A rabbitpox virus serpin gene controls host range by inhibiting apoptosis in restrictive cells. J. Virol. 69, 7688-7698 (1995).

107. Shisler, J. L., Isaacs, S. N. \& Moss, B. Vaccinia virus serpin-1 deletion mutant exhibits a host range defect charracterized by low levels of intermediate and late mRNAs. Virology 262 298-311 (1999).

108. Macen, J. L. et al. Differential inhibition of the Fas- and granule-mediated cytolysis pathways by the orthopoxvirus cytokine response modifier A/SPI-2 and SPI-1 protein. Proc. Natl Acad. Sci. USA 93, 9108-9113 (1996).

109. Moon, K. B., Turner, P. C. \& Moyer, R. W. SPI-1-dependent host range of rabbitpox virus and complex formation with cathepain $\mathrm{G}$ is associated with serpin motifs. J. Virol. $\mathbf{7 3}$ 8999-9010 (1999).

110. Wallich, R., Simon, M. M. \& Mullbacher, A. Virulence of mousepox virus is independent of serpin-mediated control of cellular cytotoxicity. Viral Immunol. 14, 71-81 (2001).

111. Kettle, S., Blake, N. W., Law, K. M. \& Smith, G. L. Vaccinia virus serpins $\mathrm{B} 13 \mathrm{R}$ (SPI-2) and $\mathrm{B} 22 \mathrm{R}(\mathrm{SPI}-1)$ encode $\mathrm{M}(\mathrm{r})$ 38.5 and $40 \mathrm{~K}$, intracellular polypeptides that do not affect virus virulence in a murine intranasal model. Virology 206 136-147 (1995)

112. Legrand, F. A. et al. Induction of potent humoral and cellmediated immune responses by attenuated vaccinia virus vectors with deleted serpin genes. J. Virol. 78, 2770-2779 (2004).

113. Perkus, M. E. et al. Vaccinia virus host range genes. Virology 179, 276-286 (1990)

A classic paper summarizing the discovery that specific vaccinia host-range genes control the ability of poxviruses to infect mammalian cells of a given host species.

114. Drillien, Koehren, F. \& Kirn, A. Host-range deletion mutant of vaccinia virus defective in human cells. Virology $\mathbf{1 1 1}$ 488-499 (1981)

115. Drillien, R., Spehner, D. \& Kirn, A. Host range restriction of vaccinia virus in Chinese hamster ovary cells: relationship to shutoff of protein synthesis. J. Virol. 28, 843-850 (1978).

116. Hruby, D. E., Lynn, D. L., Condit, R. C. \& Kates, J. R. Cellular differences in the molecular mechanisms of vaccinia virus host-range restriction. J. Gen. Virol. 47, 485-488 (1980).

117. Gillard, S., Spehner, D. \& Drillien, R. Mapping of a vaccinia host range sequence by insertion into the viral thymidine kinase gene. J. Virol. 53, 316-318 (1985).

118. Gillard, S., Spehner, D., Drillien, R. \& Kirn, A. Localization and sequence of a vaccinia virus gene required for multiplication in human cells. Proc. Natl Acad. Sci. USA 83, 5573-5577 (1986).

119. Ramsey-Ewing, A. \& Moss, B. Apoptosis induced by a postbinding step of vaccinia virus entry into Chinese hamster ovary cells. Virology 242, 138-149 (1998).

120. Spehner, D., Gillard, S., Drillien, R. \& Kirn, A. A cowpox virus gene required for multiplication in Chinese hamster ovary cells. J. Virol. 62, 1297-1304 (1988).

Another classic paper showing that a specific gene, $\mathrm{CHOhr}$ (or CP77), is required for the replication of cowpox virus in $\mathrm{CHO}$ cells.

121. Oguiura, N., Spehner, D. \& Drillien, R. Detection of a protein encoded by the vaccinia virus $C 7 L$ open reading frame and study of its effect on virus multiplication in different cell lines. J. Gen. Virol. 74, 1409-1413 (1993).

22. Chen, W., Drillien, R., Spehner, D. \& Buller, R. M. L. Restricted replication of ectromelia virus in cell culture correlates with mutation in virus-encoded host range genes. Virology 187, 433-442 (1992).

123. Ramsey-Ewing, A. \& Moss, B. Restriction of vaccinia virus replication in $\mathrm{CHO}$ cells occurs at the stage of vira intermediate protein synthesis. Virology 206, 984-993 (1995).

124. Ink, B. S., Gillbert, C. S. \& Evans, G. I. Delay of vaccinia virus-induced apoptosis in nonpermissive Chinese hamster ovary cells by the cowpox virus $\mathrm{CHOhr}$ and adenovirus $\mathrm{E} 1 \mathrm{~B}$ $19 K$ genes. J. Virol. 69, 661-668 (1995).

125. Hsiao, J.-C., Chung, C.-S., Drillien, R. \& Chang, W. The cowpox virus host range gene, $\mathrm{CP} 77$, affects phosphorylation of elF2 $\alpha$ and vaccinia viral translation in apoptotic HeLa cells. Virology 329, 199-212 (2004).

126. Ramsey-Ewing, A. L. \& Moss, B. Complementation of a vaccinia virus host-range $\mathrm{K} 1 \mathrm{~L}$ gene deletion by the nonhomologous CP77 gene. Virology 222, 75-86 (1996).

127. Chung, C.-S., Vasilevskaya, I. A., Wang, S.-C., Bair, C.-H. \& Chang, W. Apoptosis and host restriction of vaccinia virus in RK13 cells. Virus Res. 52, 121-132 (1997)
128. Sutter, G., Ramseyewing, A., Rosales, R. \& Moss, B. Stable expression of the vaccinia virus $\mathrm{K} 1 \mathrm{~L}$ gene in rabbit cells complements the host range defect of a vaccinia virus mutant. J. Virol. 68, 4109-4116 (1994).

129. Mosavi, L. K., Cammett, T. J., Desrosiers, D. C. \& Peng, Z $Y$. The ankyrin repeat as molecular architecture for protein recognition. Protein Sci. 13, 1435-1448 (2004).

130. Tartaglia, J. et al. NYVAC: a highly attenuated strain of vaccinia virus. Virology 188, 217-232 (1992).

131. Meyer, H., Sutter, G. \& Mayr, A. Mapping of deletions in the genome of the highly attenuated vaccinia virus MVA and their influence on virulence. J. Gen. Virol. 72, 1031-1038 (1991).

132. Carroll, M. W. \& Moss, B. Host range and cytopathogenicity of the highly attenuated MVA strain of vaccinia viruspropagation and generation of recombinant viruses in a nonhuman mammalian cell line. Virology 238, 198-211 (1997)

133. Drexler, I., Heller, K., Wahren, B., Erfle, V. \& Sutter, G. Highly attenuated modified vaccinia virus Ankara replicates in baby hamster kidney cells, a potential host for virus propagation, but not in various human transformed and primary cells. J. Gen. Virol. 79, 347-352 (1998)

134. Blanchard, T. J., Alcami, A. Andrea, P. \& Smith, G. L. Modified vaccinia virus Ankara undergoes limited replication in human cells and lacks several immunomodulatory proteins- implications for use as a human vaccine. J. Gen. Virol. 79, 1159-1167 (1998).

135. Wyatt, L. S. et al. Marker rescue of the host range restriction defects of modified vaccinia virus ankara. Virology 251 334-342 (1998)

136. Mossman, K., Lee, S. F., Barry, M., Boshkov, L. \& McFadden, G. Disruption of M-T5, a novel myxoma virus gene member of the poxvirus host range superfamily, results in dramatic attenuation of myxomatosis in infected European rabbits. J. Virol. 70, 4394-4410 (1996).

137. Langland, J. O. \& Jacobs, B. L. The role of the PKRinhibitory genes, E3L and $\mathrm{K} 3 \mathrm{~L}$, in determining vaccinia virus host range. Virology 299, 133-141 (2002). An important paper showing how two closely related vaccinia host-range genes, E3L and K3L, differ in the mechanisms by which they mediate vaccinia tropism in a variety of mammalian cells.

138. Smith, E. J., Marié, I., Prakash, A., García-Sastre, A. \& Levy, D. E. IRF3 and IRF7 phosphorylation in virus-infected cells does not require double-stranded RNA-dependent protein kinase $\mathrm{R}$ or IKB kinase but is blocked by vaccinia virus $\mathrm{E} 3 \mathrm{~L}$ protein. J. Biol. Chem. 276, 8951-8957 (2001).

139. Beattie, E. et al. Host-range restriction of vaccinia virus E3L specific deletion mutants. Virus Genes 12, 89-94 (1996).

140. Beattie, E., Paoletti, E. \& Tartaglia, J. Distinct patterns of IFN sensitivity observed in cells infected with vaccinia K3L- and E3L-mutant viruses. Virology 210, 254-263 (1995).

141. Fang, Z.-Y. et al. Expression of vaccinia E3L and K3L genes by a novel recombinant canarypox HIV vaccine vector enhances HIV-1 pseudovirion production and inhibits apoptosis in human cells. Virology 291, 272-284 (2001).

142. Hornemann, S. et al. Replication of modified vaccinia virus Ankara in primary chicken embryo fibroblasts requires expression of the interferon resistance gene E3L. J. Virol. 77 , 8394-8407 (2003).

143. Senkevich, T. G., Koonin, E. V. \& Buller, R. M. A poxvirus protein with a RING zinc finger motif is of crucial importance for virulence. Virology 198, 118-128 (1994).

144. Senkevich, T. G., Wolffe, E. J. \& Buller, R. M. L. Ectromelia virus RING finger protein is localized in virus factories and is required for virus replication in macrophages. J. Virol. 69, 4103-4111 (1995).

145. Huang, J. et al. The poxvirus p28 virulence factor is an E3 ubiquitin ligase. J. Biol. Chem. 279, 54110-54116 (2004)

146. Nerenberg, B. T. H. et al. The poxviral RING protein p28 is a ubiquitin ligase that targets ubiquitin to viral replication factories. J. Virol. 79, 597-601 (2005).

147. Fenner, F. \& Ross, J. Myxomatosis (eds Thompson, G. V. \& King, C. M.) (Oxford Univ. Press, 1994).

148. Rubins, K. H. et al. The host response to smallpox: analysis of the gene expression program in peripheral blood cells in a non-human primate model. Proc. Natl Acad. Sci. USA 101, 15190-15195 (2004)

149. Jahrling, P. B. et al. Exploring the potential of variola virus infecton of cynomolgus macaques as a model for human smallpox. Proc. Natl Acad. Sci. USA 101, 15196-15200 (2004)

150. Bieniasz, P. D. Intrinsic immunity: a front-line defense against viral attack. Nature Immunol. 5, 1109-1115 (2004). This excellent review describes several host molecules that mediate the intrinsic antiviral responses of mammalian cells at the cellular level. Several of these host responses might well affect multiple virus groups. 
151. Buller, R. M. \& Fenner, F. in The Mouse in Biomedical Research (eds Fox, J. G. et al.) (American College of Laboratory Animal Medicine, in the press).

152. Mahalingam, S., Foster, P. S., Lobigs, M., Farber, J. M. \& Karupiah, G. Interferon-inducible chemokines and immunity to poxvirus infections. Immunol. Rev 177, 127-133 (2000).

153. Smith, V. P. \& Alcami, A. Inhibition of interferons by ectromelia virus. J. Virol. 76, 1124-1134 (2002).

154. Mullbacher, A. Cell-mediated cytotoxicity in recovery from poxvirus infections. Rev. Med. Virol. 13, 223-232 (2003).

155. Brownstein, D. G., Bhatt, P. N., Gras, L. \& Jacoby, R. O. Chromosomal locations and gonadal dependence of genes that mediate resistance to ectromelia (mousepox) virusinduced mortality. J. Virol. 65, 1946-1951 (1991).

156. O'Neill, H. C. Resistance to ectromelia virus infection in mice. Analysis of $\mathrm{H}-2$-linked gene effects. Arch. Virol. 118, 253-259 (1991).

157. Brownstein, D. G., Bhatt, P. N. \& Gras, L. Ectromelia virus replication in major target organs of innately resistant and susceptible mice after intravenous infection. Arch. Virol. 129 65-75 (1993)

158. Delano, M. L. \& Brownstein, D. G. Innate resistance to letha mousepox is genetically linked to the NK gene complex on chromosome 6 and correlates with early restriction of virus replication by cells with an NK phenotype. J. Virol. 69, 5875-5877 (1995)

159. Brownstein, D. G. \& Gras, L. Chromosome mapping of $R m p-4$, a gonad-dependent gene encoding host resistance to mousepox. J. Virol. 69, 6958-6964 (1995).

160. Brownstein, D. G. \& Gras, L. Differential pathogenesis of lethal mousepox in congenic Dba/2 mice implicates natural killer cell receptor NKR-P1 in necrotizing hepatitis and the fifth component of complement in recruitment of circulating leukocytes to spleen. Am. J. Pathol. 150, 1407-1420 (1997)

161. Karupiah, G., Chen, J. H., Nathan, C. F., Mahalingam, S. \& Macmicking, J. D. Identification of nitric oxide synthase 2 as an innate resistance locus against ectromelia virus infection. J. Virol. 72, 7703-7706 (1998).

162. Mahalingam, S. et al. Enhanced resistance in STAT6deficient mice to infection with ectromelia virus. Proc. Natl Acad. Sci. USA 98, 6812-6817 (2001)

163. Xu, D. et al. The multidrug resistance gene mdr1a influences resistance to ectromelia virus infection by mechanisms other than conventional immunity. Immunol. Cell Biol. 82, 462-470 (2004).

164. Chaudhri, G. et al. Polarized type 1 cytokine response and cell-mediated immunity determine genetic resistance to mousepox. Proc. Natl Acad. Sci. USA 101, 9057-9062 (2004).

Provides a useful up-to-date summation of what is known about the importance of $\mathrm{T}_{\mathrm{H}}$-polarized responses in determining whether a given poxvirus infection will cause pathology or resolve.

165. Buller, R. L. M. \& Palumbo, G. J. Poxvirus pathogenesis. Microbiol. Rev. 55, 80-122 (1991).

166. Mullbacher, A. \& Lobigs, M. Creation of killer poxvirus could have been predicted. J. Virol. 75, 8353-8355 (2001).

167. Karupiah, G. Type 1 and type 2 cytokines in antiviral defense. Vet. Immunol. Immunopathol. 63, 105-109 (1998).

168. Jackson, R. J. et al. Expression of mouse interleukin- 4 by a recombinant ectromelia virus suppresses cytolytic lymphocyte responses and overcomes genetic resistance to mousepox. J. Virol. 75, 1205-1210 (2001).

This controversial paper provides data showing that the insertion of a $\mathrm{T}_{\mathrm{H}}$ 2-polarizing cytokine, IL-4, into ectromelia virus resulted in a poxvirus construct that was pathogenic in mice strains that are normally resistant to ectromelia infection, and that the ability to vaccinate against the IL-4-expressing virus was compromised.

169. Guo, Z. S. \& Bartlett, D. L. Vaccinia as a vector for gene delivery. Expert Opin. Biol. Ther. 4, 902-917 (2004).
170. Pastoret, P.-P. \& Vanderplasschen, A. Poxviruses as vaccine vectors. Comp. Immunol. Microbiol. Infect. Dis. 26 343-355 (2003)

171. Essajee, S. \& Kaufman, H. L. Poxvirus vaccines for cancer and HIV therapy. Expert Opin. Biol. Ther. 4, 1-14 (2004).

172. Franchini, G., Gurunathan, S., Baglyos, L., Plotkin, S. \& Tartaglia, J. Poxvirus-based vaccine candidates for HIV: two decades of experience with special emphasis on canarypox vectors. Expert Rev. Vaccines 3, S75-S88 (2004).

173. Bonilla-Guerrero, R. \& Poland, G. A. Smallpox vaccines: current and future. J. Lab. Clin. Med. 142, 252-257 (2003).

174. Upfal, M. J. \& Cinti, S. Smallpox vaccination and adverse cardiac events. Emerg. Infect. Dis. 10, 961-962 (2004).

175. Hodge, J. W. et al. Modified vaccinia virus Ankara recombinants are as potent as vaccinia recombinants in diversified prime and boost vaccine regimens to elicit therapeutic antitumor responses. Cancer Res. 63 7942-7949 (2003).

176. Earl, P. L. et al. Immunogenicity of a highly attenuated MVA smallpox vaccine and protection against monkeypox. Nature 428, 182-185 (2004).

Showed that the non-replicating MVA strain could stil provide robust protection against lethal challenge of monkeypox in the primate model. This indicates that MVA might also protect humans from smallpox, therefore providing a safer platform for other vaccine strategies.

177. Belyakov, I. M. et al. Shared modes of protection against poxvirus infection by attenuated and conventional smallpox vaccine viruses. Proc. Natl Acad. Sci. USA 100, 9458-9463 (2003).

178. Hel, Z. et al. Equivalent immunogenicity of the highly attenuated poxvirus-based ALVAC-SIV and NYVAC-SIV vaccine candidates in SIVmac251-infected macaques. Virology 304, 125-134 (2002)

179. Wyatt, L. S., Earl, P. L., Eller, L. A. \& Moss, B. Highly attenuated smallpox vaccine protects mice with and without immune deficiencies against pathogenic vaccinia virus challenge. Proc. Natl Acad. Sci. USA 101, 4590-4595 (2004).

180. Paoletti, E., Taylor, J., Meignier, B., Meric, C. \& Tartaglia, J. Highly attenuated poxvirus vectors: NYVAC, ALVAC and TROVAC. Dev. Biol. Stand. 84, 159-163 (1995).

181. Sutter, G. \& Staib, C. Vaccina vectors as candidate vaccines: the development of modified vaccinia virus Ankara for antigen delivery. Curr. Drug Targets Infect. Disord. 3 263-271 (2003).

182. McCurdy, L. H., Larkin, B. D., Martin, J. E. \& Graham, B. S. Modified vaccinia Ankara: potential as an alternative smallpox vaccine. Clin. Infect. Dis. 38, 1748-1753 (2004).

183. Antoine, G., Scheiflinger, F., Dorner, F. \& Falkner, F. G. The complete genomic sequence of the modified vaccinia Ankara strain: comparison with other orthopoxviruses. Virology 244, 365-395 (1998).

184. Sancho, M. C., Schleich, S., Griffiths, G. \& Krijnse-Locker, J. The block in assembly of modified vaccinia virus Ankara in HeLa cells reveals new insights into vaccinia virus morphogenesis. J. Virol. 76, 8318-8334 (2002).

185. Gallego-Gómez, J. C. et al. Differences in virus-induced cell morphology and in virus maturation between MVA and other strains (WR, Ankara, and NYCBH) of vaccinia virus in infected human cells. J. Virol. 77, 10606-10622 (2003).

186. Staib, C. et al. Transient host range selection for genetic engineering of modified vaccinia virus Ankara. Biotechniques 28 , 1137-1147 (2000).

187. Tscharke, D. C. \& Smith, G. L. Notes on transient host range selection for engineering vaccinia virus strain MVA. Biotechniques 33, 186-188 (2002).

188. Staib, C. Löwel, M., Erfle, V. \& Sutter, G. Improved host range selection for recombinant modified vaccinia virus Ankara. Biotechniques 34, 694-700 (2003).

189. Mastrangelo, M. J. \& Lattime, E. C. Virotherapy clinical trials for regional disease: in situ immune modulation using recombinant poxvirus vectors. Cancer Gene Ther $\mathbf{9}$ 1013-1021 (2002)

190. Bell, J. C., Garson, K. A., Lichty, B. D. \& Stojdi, D. F. Oncolytic viruses: programmable tumour hunters. Curr. Gene Ther. 2, 1-12 (2002).

191. Chiocca, E. A. Oncolytic viruses. Nature Rev. Cancer 2 , 938-961 (2002)

192. Lin, E. \& Nemunaitis, J. Oncolytic viral therapies. Cancer Gene Ther. 11, 643-664 (2004).

193. Zeh, H. J. \& Bartlett, D. L. Development of a replicationselective, oncolytic poxvirus for the treatment of human cancers. Cancer Gene Ther. 9, 1001-1012 (2002).

194. Thorne, S. H. \& Kirn, D. H. Future directions for the field of oncolytic virotherapy: a perspective on the use of vaccinia virus. Expert Opin. Biol. Ther. 4, 1-15 (2004). Provides a useful perspective on the exploitation of vaccinia virus-based vectors for cancer therapy.

195. Yu, Y. A. et al. Visualization of tumors and metastases in live animals with bacteria and vaccinia virus encoding lightemitting proteins. Nature Biotechnol. 22, 313-320 (2004).

196. McCart, J. A. et al. Systemic cancer therapy with a tumorselective vaccinia virus mutant lacking thymidine kinase and vaccinia growth factor genes. Cancer Res. 61, 8751-8757 (2001)

197. McCart, J. A. et al. Oncolytic vaccinia virus expressing the human somatostatin receptor SSTR2: molecular imaging after systemic delivery using ${ }^{111} \mathrm{n}$-pentetreotide. Mol. Ther. 10, 553-561 (2004).

198. Galmiche, M. C., Rindisbacher, L., Wels, W., Wittek, R. \& Buchegger, F. Expression of a functional single chain antibody on the surface of extracellular enveloped vaccinia virus as a step towards selective tumour cell targeting. J. Gen. Virol. 78, 3019-3027 (1997).

199. Fenner, F. in The Mouse in Biomedical Research Vol. II (eds H. L. Fox, J. D. Small and J. G. Fox) 213 (Academic Press, 1982).

200. Vilcek, J. Why are rabbits uniquely sensitive to myxoma virus? Cherchez l'interferon! Nature Immunol. 5, 1205-1206 (2004).

Acknowledgements

The author holds a Canada Research Chair in Molecular Virology, and is supported by operating grants from the Canadian Institutes of Health Research and the NCIC of Canada. The help of D. Hall in preparing the manuscript and the critical feedback from M. Stanford and M. Barry are gratefully appreciated.

Competing interests statement

The author declares competing financial interests: see Web version for details.

\section{O) Online links}

\section{DATABASES}

The following terms in this article are linked online to:

Entrez: http://www.ncbi.nlm.nih.gov/Entrez/

Cowpox virus | Ectromelia virus | molluscum contagiosum virus | myxoma virus | vaccinia virus | variola virus

Infectious Disease Information:

http://www.cdc.gov/ncidod/diseases/index.htm

Monkeypox |SARS | smallpox

SwissProt: http://www.ca.expasy.org/sprot/

Nck | N-WASP | SPI-1 | WIP

\section{FURTHER INFORMATION}

Poxvirus Bioinformatics Resouce Center:

http://www.poxvirus.org

WHO smallpox slide set:

http://www.who.int/emc/diseases/smallpox/slidese

Grant McFadden's laboratory:

http://www.robarts.ca/biotherapeutics

Access to this links box is available online. 